Territorios 38 / Bogotá, 2018, pp. 15-40

ISSN: 0123-8418

ISSNe: 2215-7484

Dinámicas sociales y reconfiguraciones territoriales contemporáneas

\title{
Centros Comerciales a Cielo Abierto como política de renovación de las centralidades tradicionales en el Conurbano Bonaerense
}

Open-Air Shopping Complexes as a Renewal Policy for Traditional Centralities in Greater Buenos Aires

Centros Comerciais a Céu Aberto como Política de Renovação das Centralidades Tradicionais no Grande Buenos Aires

Lorena Vecslir ${ }^{*}$

Luciana Rodríguez $^{* *}$

Recibido: 23 de marzo de 2017

Aprobado: 9 de agosto de 2017

Doi: http://dx.doi.org/10.12804/revistas.urosario.edu.co/territorios/a.5499

Para citar este artículo:

Vecslir, L. \& Rodríguez, L. (2018). Centros Comerciales a Cielo Abierto como política de renovación de las centralidades tradicionales en el Conurbano Bonaerense. Territorios, (38), 15-40. doi: http://dx.doi. $\operatorname{org} / 10.12804 /$ revistas.urosario.edu.co/territorios/a.5499

* Arquitecta de la Universidad de Buenos Aires - UBA, máster en Proyectación Urbanistica y doctora en Urbanismo de la Universidad Politécnica de Cataluña. Investigadora adjunta del CONICET y del Instituto de Geografía (FFyL, UBA). Correo electrónico: lorena.vecslir@conicet.gov.ar, ORCID: http://orcid. org/0000-0003-0130-7808

** Arquitecta de la Universidad Nacional de Córdoba - UNC. Magister en Teoría y Práctica del Proyecto de Arquitectura de la Universidad Politécnica de Cataluña. Becaria doctoral del CONICET con sede en el Instituto de Geografía (FFyL, UBA). Correo electrónico: lucianarodriguez@conicet.gov. ar, ORCID: http://orcid. org/0000-0001-7625-9623 
Palabras clave

Centralidad, comercio a cielo abierto, renovación urbana, región metropolitana de Buenos Aires, identidad.

Keywords

Centrality, Open-air shopping complexes, Urban renewal, Metropolitan Region of Buenos Aires, Identity.

Palavras-chave

Centralidade, Comércio a Céu Aberto, Renovação Urbana, Região Metropolitana de Buenos Aires, Identidade.

\section{territarias 38}

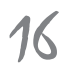

\section{RESUMEN}

El presente trabajo propone un análisis comparativo de diversas iniciativas de renovación de las centralidades tradicionales en el Conurbano Bonaerense bajo el modelo de Centros Comerciales a Cielo Abierto. Se parte del origen del concepto y de las primeras experiencias en Estados Unidos y Europa entre los años setenta y ochenta, para luego relacionarlas con la circulación de ideas hacia Latinoamérica una década más tarde y, en especial, con su reinterpretación y aplicación en la región metropolitana de Buenos Aires desde inicios de los 2000. Se estudia el patrón de distribución territorial de estas políticas, el tamaño y tipo de operaciones, el grado de realización, los actores involucrados y la articulación con otras políticas públicas locales. Con base en este análisis, se reflexiona, finalmente, acerca de la imagen urbana, del perfil comercial y de las prácticas sociales promovidas, así como de sus alcances y limitaciones frente a las diferentes formas y procesos de la centralidad metropolitana, y la capacidad de vinculación con otras políticas urbanas de escala territorial.

\section{ABSTRACT}

The present work proposes a comparative analysis of several renovation initiatives of the traditional centralities in Greater Buenos Aires under the model of Open-air shopping complexes. The paper starts with the origin of the concept and the first experiences in the USA and Europe between the 70's and 80's, in order to relate them with the circulation of ideas towards Latin America a decade later and, especially, to its reinterpretation and application in the Metropolitan Region of Buenos Aires since the beginning of the year 2000. The territorial distribution pattern of these policies, size and type of operations, degree of accomplishment, actors involved and articulation with other local public policies are studied as well. Based on this analysis, the urban image, the commercial profile and social practices promoted will be considered, as well as its scope and limitations in relation to the different forms and processes of metropolitan centrality, and its linkage capacity with other urban policies of territorial scale.

\section{Resumo}

O presente trabalho propõe uma análise comparativa de diversas iniciativas de renovação das centralidades tradicionais no Grande Buenos Aires sob o modelo de Centros Comerciais a Céu Aberto. Parte-se da origem do conceito e as primeiras experiências nos EUA e na Europa entre os anos '70 e '80, para logo relacioná-las com a circulação de ideias à Latino-América uma década mais tarde e, em especial, a sua reinterpretação e aplicação na região metropolitana de Buenos Aires desde inícios dos 2000. Estuda-se o patrão de distribuição territorial destas políticas, tamanho e tipo de operações, grau de realização, atores envolvidos e articulação com outras políticas públicas locais. Com base a esta análise, se reflete finalmente acerca da imagem urbana, perfil comercial e práticas sociais promovidas, assim como os seus alcances e limitações frente às diferentes formas e processos da centralidade metropolitana, e capacidade de vinculação com outras políticas urbanas de escala territorial. 


\section{Introducción}

En el marco de un programa financiado por el Banco Interamericano de Desarrollo (BID), desde inicios de los 2000, se ha venido formulando una serie de acuerdos entre la Confederación Argentina de la Mediana Empresa (CAME) y diversos municipios del Conurbano Bonaerense (en adelante, $\mathrm{CB}^{1}$ ) con el fin de impulsar la transformación de sus áreas centrales tradicionales bajo el modelo de Centros Comerciales a Cielo Abierto (en adelante, CCCA).

La sumatoria de estas iniciativas de escala local - que ya involucran a diez de los 24 municipios del $\mathrm{CB}^{2}$ - da cuenta de la implementación, cada vez más generalizada en la región metropolitana, de un tipo de política urbana destinada a intervenir en el mejoramiento de las áreas centrales tradicionales de las principales localidades. Esta implementación es justificada, en la mayoría de los casos, como respuesta a la progresiva pérdida de atracción de dichas centralidades y a la declinación de la dinámica comercial minorista, ante el surgimiento de los shoppings y otras grandes superficies comerciales, así como también en la degradación ambiental, la proliferación del comercio ambulante y la contaminación visual, abogando siempre por el 'fortalecimiento de la identidad local'.

Las acciones concertadas a partir de estos acuerdos, que operan como alianzas entre los comerciantes, el sector público y diversas organizaciones privadas, se orientan, por un lado, al reordenamiento del espacio público de las principales calles comerciales (peatonalización, cambios de solado, soterramiento del cableado eléctrico, nueva luminaria, códigos de cartelería, etc.) y, por otro, a la instrucción para la promoción comercial (campañas de marketing, eventos culturales, etc.) y capacitación empresarial.

Aunque algunas intervenciones de CCCA se inscriben en el marco de planes urbanos a escala municipal, en general presentan ciertas dificultades para articularse con el resto de políticas públicas locales en materia de transporte, manejo de residuos, vivienda social e, incluso, espacio público. Tampoco existen análisis territoriales más amplios — ni se registra la intencionalidad de realizarlos- que prevean estas operaciones a escala de toda la región metropolitana, con el fin de vincularlas con políticas sectoriales de movilidad y accesibilidad desde el transporte público (potencial competencia con las grandes superficies comerciales orientadas al automóvil), y que, desde una perspectiva más vasta, pongan en discusión las competencias y complementariedades del sistema de centralidades tradicionales en conjunto con los enclaves emergentes del ocio y del consumo, así como con la permanencia y el rol estructurante de antiguos corredores comerciales suburbanos, característicos de la región metropolitana.

Paralelamente, resulta recurrente el uso directo de modelos extranjeros de intervención y gestión, sobre la base de antecedentes de CCCA, en su mayoría españoles. En este sentido, la ausencia de un análisis crítico que determine las diferencias
- Se le llama Conurbano Bonaerense ( $C B$ ) al territorio conformado por los 24 municipios que hacen parte de la 1." y 2." corona de la región metropolitana de Buenos Aires y que, en su conjunto, comprenden un área de $3630 \mathrm{~km}^{2}$ y una población actual de aproximadamente diez millones de habitantes.

${ }^{2}$ Con distinto grado de concreción, existen iniciativas de CCCA en los municipios de Morón, Lomas de Zamora, San Fernando, San Isidro, Tigre, Vicente López, Moreno, Hurlingham, Tres de Febrero y San Miguel. Fuera del CB, en la tercera corona metropolitana, también se registran acuerdos con los municipios de Pilar y Luján.

territarias 38

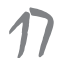


${ }^{3}$ En el artículo "Centros comerciales de área urbana. Estudio de las principales experiencias extranjeras" (Molinillo Jiménez, 2001) puede encontrarse un desarrollo detallado de los nombres que estas asociaciones adoptan en diferentespaises del mundo.

\section{territarias 38}

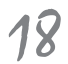

estructurales con los lugares específicos de actuación pareciera conducir a un alejamiento del rescate identitario que se persigue. Por caso: la eliminación del comercio ambulante considerado un "estorbo a la vida pública".

Dentro de este marco, se plantean, entre otros interrogantes, los siguientes: ¿qué lugares se eligen para intervenir? ¿Qué tipos de "imagen" urbana y de perfil comercial se promueven con estas acciones? ¿Recuperar las calles para quiénes? ¿Qué prácticas sociales fomentan las intervenciones? ¿Cuáles son sus alcances y limitaciones frente a las diferentes formas y procesos de la centralidad metropolitana? ¿Qué potencialidades de articulación presentan con las políticas locales y territoriales?

Como primera aproximación a estas cuestiones, el presente trabajo se propone estudiar de manera comparativa las acciones de renovación urbana promovidas por la CAME en el CB. En primer lugar, se busca rastrear el origen del concepto y relacionar las primeras experiencias de CCCA en Estados Unidos y Europa entre los años setenta y ochenta, con la posterior circulación de ideas hacia Latinoamérica, una década más tarde y, en especial, con las iniciativas en la región metropolitana de Buenos Aires desde inicios de los años 2000. En segundo término, se realiza un análisis comparado de estas acciones en el CB: su patrón de distribución territorial, su tamaño y tipo de operaciones, su grado de realización, los actores involucrados y las características específicas de intervención y gestión, la articulación con otras políticas públicas locales, los grados de compromiso de los acuerdos, etc. Con base en este análisis se reflexiona, por último, acerca de las transformaciones socio-territoriales promovidas en relación con aquellas cuestiones que quedan relegadas frente a las estrategias de promoción comercial y la búsqueda de un ambiente urbano "atractivo" para el visitante.

\section{Origen del concepto y primeras experiencias de CCCA}

\subsection{Transferencias hacia \\ Latinoamérica y la región metropolitana de Buenos Aires}

Si bien el término Centro Comercial a Cielo Abierto (CCCA) puede variar según el lugar geográfico donde se desarrolle ${ }^{3}$, en general alude a dos cuestiones sustanciales: la centralidad del área respecto de la aglomeración donde se asienta y el carácter descubierto de los comercios involucrados, en oposición a la concentración de estos bajo una única superficie cubierta - como los shopping malls, galerías comerciales, grandes tiendas, etc.- (Molinillo Jiménez, 2001).

Aunque rastrear el origen de los CCCA es difícil debido a la falta de convención sobre su nombre y de sistematización sobre sus implicancias, existe consenso sobre su primera manifestación en los años sesenta en Canadá. Allí un grupo de pequeños empresarios logró generar una legislación para el desarrollo de una entidad privada y autónoma, que imponía impuestos a los due- 
ños de los comercios de un determinado sector de la ciudad para financiar tareas de revitalización urbana (Hoyt, 2006; Hoyt \& Gopal-Agge, 2007). Sin embargo, diez años después, fue en Estados Unidos donde cobró más fuerza debido, entre otras causas, al declive de los centros urbanos tradicionales frente al acelerado spraw $l$ del crecimiento residencial y al desarrollo de nuevos enclaves y formatos comerciales en la periferia de las ciudades. A estos factores se sumó la dificultad de financiamiento de los gobiernos locales a causa de la disminución de la base tributaria, lo que derivó en el crecimiento de las alianzas públicoprivadas para asumir las operaciones de revitalización y mantenimiento urbano (Hoyt \& Gopal-Agge, 2007). Así surgieron los "Distritos de Mejora de Negocios" o Business Improvement Districts (BIDs) ${ }^{4}$, definidos como un grupo de propietarios y comerciantes que acuerda proveer de un grado adicional de servicios (seguridad, limpieza, promoción de eventos, asistencia social, etc.) a un área geográfica específica, a través de la imposición de impuestos añadidos a todas sus propiedades o negocios (Mitchell, 2001). Según Bratos Martín, la característica fundamental de este tipo de gestión reside en que "[...] una vez aprobado el BID, mediante un convenio con el Ayuntamiento, normalmente de cinco años, todos los propietarios comerciales de la zona a la que hace referencia se convierten en miembros, estén o no de acuerdo con la formación del mismo. Por tanto, quedan obligados a abonar el recargo obligatorio acordado que, en el caso estadounidense, recaerá sobre los propietarios y no sobre los arrendatarios" (2013, p. 284).

La primera "transferencia de políticas" (policy transfer $)^{5}$ vinculadas a los BID desde Estados Unidos hasta Europa se realizó a través del Reino Unido. En este país, las ideas acerca del nuevo modelo de gestión encontraron un campo fértil de desarrollo dada la experiencia previa en esta temática, adquirida a través de la figura de "Administración del Centro Urbano" o Town Centre Management (TCM). La diferencia de los TCM con los BID radicaba en dos cuestiones: el área de aplicación no estaba claramente definida y la financiación se obtenía a través de contribuciones voluntarias tanto del sector público como del privado. Fue justamente este último factor el que dio lugar a la transformación de los TCM por la figura de los BID, que buscaba corregir el beneficio que ciertos actores obtenían indirectamente sin efectuar aportes.

Con algunas variaciones, el modelo se expandió después por otros países como Alemania y Holanda. En España, particularmente, el instrumento utilizado fue el de Centros Comerciales Abiertos (CCA), fortalecido por el desarrollo de legislaciones específicas dentro de algunas comunidades autónomas como Extremadura o Andalucía (Bratos Martín, 2013). Según la definición expresada en el I Congreso Nacional de Centros Comerciales Abiertos (Huelva, 2000), los CCA constituyen una “[...] fórmula de organización comercial, con una imagen y estrategia propia, que cuenta con la implicación de todos los
4 Según Gopal (2003; en Bratos Martín, 2013) las actividades que involucran a los BID pueden dividirse en tresgruposprincipales, donde cada uno sienta las bases para el desarrollo del siguiente: mejora delentorno (mantenimiento y limpieza del área y consolidación de la seguridad), acciones de marketing del consumidory acciones que tratan de asegurar la sostenibilidad del BID a largo plazo.

5 Término que describe la transferencia de conocimientos y prácticas empleadas en un contexto determinado hacia otro contexto, en donde la temática de revitalización urbana se está volviendo muy popular debido, entre otras causas, al poco involucramiento que el sector público está teniendo en su desarrollo (Hoyt, 2006). El mismo autor advierte sobre el problema que puede representar el desarrollo de politicas con base en evidencia subjetiva, en lugar de ponderarlo con la situación económica, la legislación y otros componentes diferenciales entre los contextos de exportación eimportación.

territarias 38

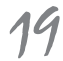


${ }^{6}$ Véase, por ejemplo, la compilación de trabajos editada por Fernando Carrión (2001) que incluye estudios de caso sobre la preservación de centroshistóricosen América Latina y reflexiones teóricas acerca del paso de la conservación monumental a la rehabilitación urbana integral, las instituciones, los actores y los temas emergentes en la conservación patrimonial.

7 Cabe citar, por ejemplo, el programa "Volvamos al centro", impulsado en los años noventa y génesis del llamado "Modelo Lima". La campaña estaba dirigida a los descendientes de la oligarquia limeña que habian abandonado el centro en los años cuarenta, como si el centro estuviera vacio o "perdido" (Ludeña, 2002).

${ }^{8}$ En esta dirección, Rojas (2004) analiza diversos casos de financiamiento $y$ ejecución de programas de rehabilitación urbana.

\section{territarias 38}

agentes de un área delimitada de una ciudad, con una concepción global de oferta comercial, servicios, cultura y ocio" (Asociación Provincial de Empresarios de Comercio de Huelva, 2000).

Por tanto, mientras que los BIDs norteamericanos se configuran, ante todo, como un modelo de gestión capaz de dotar a una zona de una serie de servicios adicionales a los ya provistos por la Administración Pública, a partir de la imposición de una cuota obligatoria, los CCA españoles hacen recaer sobre el sector público la principal responsabilidad del financiamiento, teniendo en cuenta dos tipos de actuaciones: aquellas que conducen a la renovación de las estructuras para mejorar el atractivo comercial de la zona, y aquellas que potencian el asociacionismo y las actuaciones conjuntas del pequeño comercio (Molinillo Jiménez, 2001). Las primeras, generalmente enmarcadas dentro de planes integrales de mejora o rehabilitación de centros históricos, conllevan operaciones vinculadas a la mejora del espacio público y la creación de una imagen unitaria, a lo que además se intentan sumar condiciones más independientes de gerenciamiento, a través de la conformación de un consorcio responsable de llevarlas a cabo.

En América Latina, paralelamente al desarrollo de estas experiencias, las áreas centrales tradicionales de las grandes metrópolis sufrían importantes transformaciones: la acelerada pérdida de sus funciones de comando y el traslado del poder económico hacia nuevos centros corporativos periféricos a la ciudad compacta, el progresivo deterioro del patrimonio edilicio, la proliferación de comercio popular o de tipo ambulante, episodios de tugurización residencial, etc. En este marco, y desde una concepción del "centro" como el lugar histórico-fundacional donde se establecieron las primeras instituciones y equipamientos públicos en torno a la plaza como principal lugar representativo, las operaciones de mejora del espacio público, peatonalización, expulsión del comercio callejero, recuperación del patrimonio arquitectónico y promoción de usos culturales y turísticos resultaron políticas comunes en la rehabilitación de los centros históricos de diversas metrópolis (Lima, Bogotá, Panamá, Quito, México) durante los años noventa ${ }^{6}$. Bajo un enfoque "monumentalista" del centro, estas intervenciones se apoyaron en la voluntad de recuperación de determinados valores morfológicos y simbólicos, como "memoria" de unas funciones cívicas y de gobierno, $\mathrm{y}$ de una población residente que desde inicios del siglo xx fue perdiendo intensidad ininterrumpidamente, en la mayoría de los casos (Carrión, 2005) ${ }^{7}$.

Este tipo de políticas tuvo la virtud de poner en valor la riqueza patrimonial de los centros históricos desde la acción pública, pero no ha sido sino hasta esta década que se ha instalado la discusión en torno a las cuestiones relacionadas con el financiamiento de las políticas de recuperación de áreas urbanas centrales ${ }^{8}$, así como con los modos de gerenciamiento y promoción del comercio de calle frente a la competencia de las grandes superficies comerciales - $-\mathrm{y}$ 
también del comercio ilegal-. En este sentido, resulta clave el rol de organismos como el Banco Interamericano de Desarrollo (BID), la Unesco, la Junta de Andalucía - y otras fuentes de financiamiento nacionales e internacionales-. Asimismo, según Carrión (2007), cobran vital importancia el sector del turismo, que a su vez arrastra otros servicios como los culturales, hoteleros, comerciales, inmobiliarios, etc.; la rehabilitación edilicia, que dinamiza el sector de la construcción y el mercado inmobiliario; y el comercio (formal e informal), como protagonista indiscutible en el proceso de transformación.

Desde esta perspectiva, las ventajas de "recuperar la identidad y fortalecer la centralidad histórica" comienzan a vincularse con los denominados procesos de gentrificación, turistificación, e incluso boutiquización de las áreas centrales "que eliminan la población residente para dar paso a los usos del suelo más rentables y exclusivos (comercios, hoteles, restaurantes, bajo la lógica boutique)" (Carrión, 2007, p. 10). Como ya nos anunciaba Jane Jacobs (1961), la acentuación de estos usos puede dar lugar a procesos de "autodestrucción de la diversidad", expulsando actividades de servicios y comercio cotidiano que no pueden competir con el nuevo valor de suelo. De igual manera, los desplazamientos comerciales y económicos han sido ampliamente señalados en el contexto latinoamericano, donde los proyectos de restauración y patrimonialización de los centros urbanos históricos han implicado la expulsión de los vendedores ambulantes, así como de los indigentes y toxicómanos, con el fin de estimular la atracción y los negocios turísticos (Lorenzen Martiny, 2015, p. 282).

En el caso de Buenos Aires, y a diferencia de otras metrópolis latinoamericanas (Santiago, San Paulo, Bogotá, México D. F., etc.), el comercio de calle ha resistido los embates - tardíos pero potentes- del shopping center y de las grandes superficies comerciales, y ha concentrado en este formato los porcentajes más altos del comercio minorista9. Esto se verifica en la Capital Federal, donde hay un intenso dinamismo comercial en las principales avenidas e intercambiadores de transporte, y la proliferación de malls y nuevos centros comerciales no parece haber afectado la estructura comercial a Cielo Abierto de los distritos tradicionales (Once, Belgrano, Flores, calle Florida, Av. Santa Fe, Recoleta) ni de los nuevos distritos de la moda y el diseño (Av. Córdoba, Palermo, Av. Avellaneda, San Telmo, etc.) (Ciccolella, Vecslir \& Baer, 2015). En el CB, en cambio, el comercio de calle no siempre ha ganado la batalla contra los nuevos centros del ocio y del consumo, y la vitalidad de las áreas centrales tradicionales - e incluso su pervivencia como imaginario de centralidad- es más discutible, caso por caso ${ }^{10}$.

En este marco, con el objetivo de promover el comercio de calle frente a la competencia de las nuevas superficies comerciales - pero sobre todo del comercio ilegal (manteros y "saladitas")_—11, desde el año 2000 la CAME, mediante la firma de un convenio con el BID y el Fondo Multilateral de Inversiones (FOMIN), lleva adelante un programa
${ }^{9}$ En Argentina, los locales a "la calle" o "a cielo abierto" concentran el $75 \%$ de las ventas (http://www. areas-digital.com.ar/nota.php?id=24369) y, según un estudio elaborado por la plataforma Paseos de Buenos Aires, en la ciudad capital este porcentaje se eleva a un $82,6 \%$, lo cual relega un $17,3 \%$ de facturación a los shoppings. Muy distinto es el caso de, por ejemplo, Estados Unidos, en donde solo el $30 \%$ de los ingresos proviene de los locales pequeños (bttp://www.paseosdebuenosaires.com.ar/).

${ }^{10}$ Es importante conocer la diferencia entre centro y centralidad, términos que en este articulo se mencionan con frecuencia. Mientras que el primero se asocia con la localización o posición de un área en relación con el contexto urbano donde se inserta, el segundo se refiere a una condición, definida principalmente por la intensidad de las actividades que allíse desarrollan. Según Álvaro Domingues (2002) esta condición permite evaluar los centros por sus funciones, más que por sus formas, y evita asociarlo con las morfologias y referencias simbólicas de los centros tradicionales 0 históricos.

${ }^{11}$ Se conoce por mantero a la persona que se dedica a

tersitarios 38 
$\Leftarrow$

la venta callejera en una plaza o en la vía pública,generalmente sin permiso municipal, poniendo encima de una manta los productos a la venta. Las saladitas, por su parte, son complejosferiales (de menor tamaño que la Feria La Salada, ubicada en el partido de Lomas de Zamora) que basan su funcionamiento en la comercialización de productos de marcas apócrifas.

${ }^{12}$ En el 2006, en una jornada de evaluación de la primera fase del programa, la CAME aseguraba haber brindado capacitación a 30000 personas, asistencia técnica a 30 proyectos asociativosy a 35 CCCA en diferentes ciudades argentinas (bttp://www.redcame.org. ar/contenidos/circular/ Jornada-de-evaluaciondel-Programa-de-Fortalecimiento-al-Comercio-Minorista-convenio-CAMEBID-FOMIN.425.html).

${ }^{13}$ La primera experiencia del PROCOM, cuyo acuerdo data del año 2000 y la ejecución de la primera fase, del 2002, es en el municipio de Morón.

\section{territarias 38}

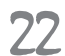

de fortalecimiento al comercio minorista ${ }^{12}$. A través de este instrumento se han planteado proyectos de renovación bajo el modelo de CCCA en las calles más emblemáticas del microcentro de la CABA, como la peatonal Florida y la Avenida Corrientes, en el barrio de Palermo, en los outlets de calle Aguirre o avenida Córdoba, en el eje Warnes especializado en repuestos para autos, etc.

Asimismo, desde su inicio, estos acuerdos han involucrado áreas urbanas externas al ámbito de la ciudad capital ${ }^{13}$ que superan el límite de la Avenida General Paz para promover el desarrollo de CCCA a lo largo de antiguas avenidas comerciales o centralidades tradicionales de diversas localidades del CB. Allí existen iniciativas en centralidades poco consolidadas (por ejemplo, en algunas localidades de Tres de Febrero) o con indicios de degradación debido a las nuevas opciones residenciales de baja densidad, al cambio de formatos y patrones de consumo, y al incremento de la movilidad privada (por ejemplo, en algunas localidades de Tigre y Vicente López); pero, sobre todo, se implantan en centros tradicionales de la primera y segunda corona metropolitana, en relación con importantes estaciones ferroviarias como Lomas de Zamora en el sur, Morón en el oeste, y San Isidro, Vicente López y Tigre Centro en el norte del Conurbano. También suelen acompañar procesos recientes de crecimiento residencial en altura, manifestando la existencia de una demanda inmobiliaria que se inclina por algunos subcentros tradicionales que renuevan parte de sus funciones (por ejemplo, Lomas de Zamora, San Miguel, Tigre Centro). Aunque sin servicios complejos, en estos subcentros aparecen locales de franquicias y usos comerciales más sofisticados, vinculados a la gastronomía especializada, cafés boutique, diseño e indumentaria de primeras marcas, y oficinas bien equipadas (Ciccolella, Vecslir \& Baer, 2015).

Los estados de planificación (de la zonificación al plan urbano o estratégico) y niveles de propuestas (programas y proyectos urbanísticos) para las áreas centrales varían según el caso. Así mismo, la historia de las subdivisiones de los términos municipales, el perfil más o menos turístico de las localidades, el nivel de especialización comercial, la proximidad a la ciudad central y el grado de accesibilidad son determinantes del tipo de centralidad a intervenir.

Por tanto, a pesar de la tradicional visión monocéntrica que asocia la idea de urbanidad a un Conurbano construido sobre una cuadrícula uniforme, estable e infinita, sin contrapuntos ni variaciones (Vecslir \& Elimbaum, 2016), existen múltiples formas de centralidad que de a poco comienzan a ser objeto de reflexión por parte de los estudios urbanos y de las políticas públicas desde los gobiernos locales, entre ellas los CCCA de los que nos ocuparemos en este artículo.

\section{Análisis comparado de las iniciativas en el Conurbano Bonaerense}

Como se señaló, el desarrollo de CCCA en Argentina ha tenido como principal 
promotor a la CAME, organización que nace en 1999 con el fin de fortalecer y mejorar el desempeño de las pymes del sector comercial y de servicios. A partir de un convenio firmado con el BID-FOMIN en el año 2000, se creó dentro del mismo organismo la Federación de Centros Comerciales a Cielo Abierto, Cascos Urbanos y Centros Históricos (FCCA), responsable del Programa de Competitividad de las Pymes en Centros Comerciales a Cielo Abierto (Procom). En el contexto de este programa, la CAME realiza foros nacionales e internacionales sobre ciudad, comercio y turismo ${ }^{14}$, y organiza anualmente visitas de dirigentes empresarios y funcionarios municipales a ciudades españolas consideradas como casos exitosos de desarrollo y gestión de CCA (Málaga, Valencia, San Sebastián, Villaviciosa-Asturias, Bilbao, Vitoria y Pamplona, entre otras).

Con base en estos antecedentes, el CCCA es definido como un "conjunto de comercios y servicios que comparten una zona geográfica de la ciudad (distrito o eje urbano central, intermedio o periférico), que deciden ofrecer una imagen unitaria de calidad sustentable" (CAME, 2016, p. 4). Siguiendo el modelo español, existen cuatro aspectos que se consideran esenciales para el desarrollo de un proyecto de CCCA: propuestas de mejoramiento urbano,
Figura 1. Conurbano Bonaerense

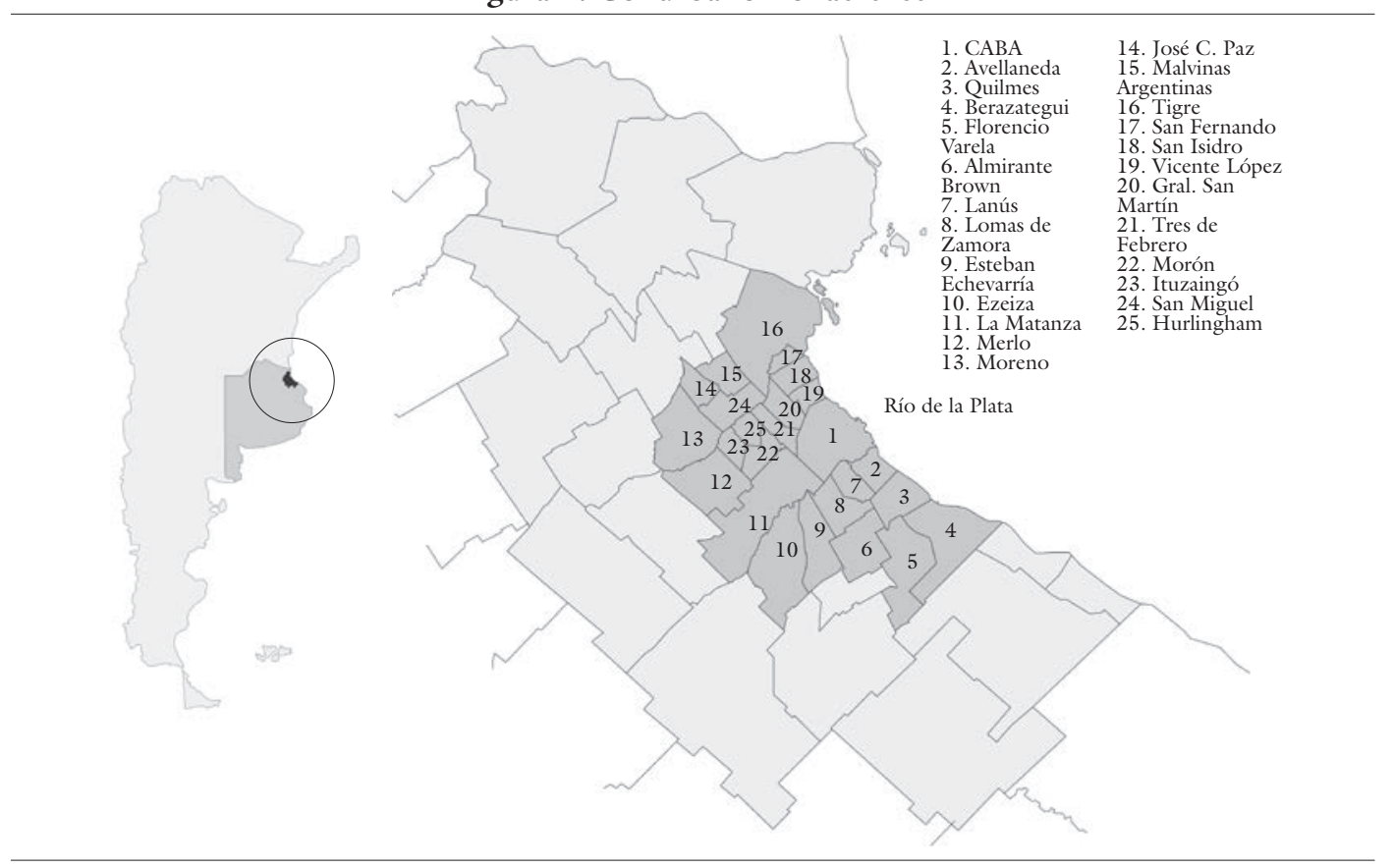

Fuente: Elaboración propia.

Centros Comerciales a Cielo Abierto como política de renovación
${ }^{14}$ El Primer Congreso Nacional sobre Experienciasen Desarrollo de Centros Comerciales a Cielo Abierto se realizó en setiembre del 2006 en Villa Mercedes, San Luis.

territarias 38 23 
${ }^{15}$ A los fines de este trabajo se seleccionaron diez ejemplos de CCCA para su comparación (uno representativo de cada municipio) de entre los 31 identificados.

${ }^{16}$ Una lógica similar puede trasladarse al patrón de distribución territorial de las intervenciones en CABA, concentradasen su mayoría en la zona del microcentro $y$ en los barrios de Palermo y Villa Crespo, sectores que cuentan con unos de los valores del suelo más altos de la ciudad.

\section{territarias 38}

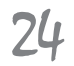

planes de promoción comercial, plan de identidad y comunicación, y esquema de dirección y gestión.

Sin embargo, aunque en la anterior definición parezca relativizarse el rol de la administración pública en pos de un fuerte asociacionismo de empresarios, en todos los ejemplos analizados dentro del $\mathrm{CB}$ los respectivos gobiernos municipales han sido los mayores responsables en la ejecución y el financiamiento de los proyectos. Así, de los cuatro elementos que desde el punto vista teórico deberían integrar un CCCA, en general, solo se desarrollan las propuestas de urbanización del espacio público, y de animación y promoción comercial; fases durante las cuales la CAME actúa como un asesor de la Municipalidad, las asociaciones de empresarios (cámaras de comercio e industria) y, eventualmente, otras organizaciones públicas y privadas (entes de turismo, colegios profesionales, entidades financieras, etc.). Luego de estos estadios no suelen configurarse entes de gestión, y solo se registra un caso de gerenciamiento a través de la formación de un consorcio ad hoc: el Paseo San Miguel, en el municipio homónimo.

Más allá de los actores involucrados y otros aspectos de gestión, cada uno de los diez acuerdos estudiados goza de especificidades que hemos intentado plasmar de manera sintética en la tabla $1^{15}$, donde se recogen los principales aspectos relativos a: localización o distribución geográfica, año del acuerdo, área afectada, agentes intervinientes, objetivos, tareas a desarrollar, fechas y grado de realización, instrumentos urbanísticos asociados y otras operaciones en la centralidad.

La primera aproximación sobre el plano de distribución territorial de los 31 CCCA relevados en el CB (figura 2) da cuenta de una localización predominante en los municipios del corredor norte (San Fernando, San Isidro, Tigre, Vicente López) y del noroeste (San Miguel, Hurlingham y Tres de Febrero - los dos últimos con iniciativas en fase de estudio o proyecto preliminar-). Las restantes cinco operaciones se ubican en partidos del eje oeste (Morón y Moreno) y del sur (Lomas de Zamora). Esta distribución coincide, en gran parte, con los sectores de nivel socioeconómico más alto del Conurbano, que a su vez cuentan con la mayor dotación de equipamientos educativos, sanitarios, culturales, comerciales y deportivos de la región ${ }^{16}$.

Por su parte, los mapas de intervención por localidad (figuras 3 y 4) —en los que se han seleccionado y esquematizado diez de los 31 CCCA relevados- dan cuenta de que la noción de centro, en general, aparece asociada a los sectores próximos a las estaciones ferroviarias, donde tradicionalmente se han concentrado las instituciones más importantes (iglesia, plaza, sede municipal) y donde se encuentra también el comercio popular. La mayor parte de los CCCA ejecutados se despliegan sobre una o dos de las calles con más dinamismo comercial, en una extensión que varía de dos a diez cuadras. La única excepción es la localidad de Morón, en donde el lugar objeto del convenio - no así de la actuación realizada- se compone de 21 manzanas. 
Tabla 1. Descripción de los Centros Comerciales a Cielo Abierto en el Conurbano Bonaerense

\begin{tabular}{|c|c|c|c|c|c|c|c|}
\hline $\begin{array}{l}\text { Ubicación/ } \\
\text { Nombre } \\
\text { y año del } \\
\text { acuerdo }\end{array}$ & Área & $\begin{array}{c}\text { Agentes } \\
\text { intervinientes }\end{array}$ & Objetivos & Tareas a desarrollar & $\begin{array}{l}\text { Fecha y grado } \\
\text { de realización }\end{array}$ & $\begin{array}{l}\text { Instrumentos } \\
\text { urbanísticos } \\
\text { asociados }\end{array}$ & $\begin{array}{l}\text { Otras ope- } \\
\text { raciones en } \\
\text { el centro }\end{array}$ \\
\hline $\begin{array}{l}\text { Localidad: } \\
\text { Morón (Mo- } \\
\text { rón) } \\
\text { Centro } \\
\text { Comercial a } \\
\text { Cielo Abier- } \\
\text { to 1.a etapa } \\
\text { (CCCAM) } \\
2000\end{array}$ & $\begin{array}{l}\text { Área determina- } \\
\text { da por las calles: } \\
\text { Mendoza hasta } \\
\text { Independencia, } \\
\text { Machado hasta } \\
\text { D. F. Sarmien- } \\
\text { to, San Martín } \\
\text { hasta R. O. del } \\
\text { Uruguay, Buen } \\
\text { Viaje hasta D. F. } \\
\text { Sarmiento } \\
\text { Total: } 21 \text { man- } \\
\text { zanas }\end{array}$ & $\begin{array}{l}\text { Municipalidad de } \\
\text { Morón; Asociación } \\
\text { Comercial e In- } \\
\text { dustrial de Morón } \\
\text { (ACIM), CAME y } \\
\text { PROCOM. } \\
\text { Financiamiento: } \\
\text { Banco Interameri- } \\
\text { cano de Desarrollo }\end{array}$ & $\begin{array}{l}\text { Reacondiciona- } \\
\text { miento de los ejes } \\
\text { comerciales del } \\
\text { centro, remodela- } \\
\text { ción de Plaza San } \\
\text { Martín y construc- } \\
\text { ción de Plaza La } \\
\text { Roche, tenien- } \\
\text { do en cuenta la } \\
\text { restructuración de } \\
\text { las manzanas que } \\
\text { rodean la estación } \\
\text { del ferrocarril }\end{array}$ & $\begin{array}{l}\text { Obras de mejoramien- } \\
\text { to y ensanche de vereda, } \\
\text { construcción de espacios } \\
\text { para equipamiento, dárse- } \\
\text { nas para estacionamiento, } \\
\text { colocación de luminarias y } \\
\text { construcción de conducto } \\
\text { pluvial. Ampliación de ve- } \\
\text { redas e instalación de nue- } \\
\text { vos refugios de colectivos y } \\
\text { luminarias }\end{array}$ & $\begin{array}{l}\text { 2002-2003 Calle Bel- } \\
\text { grano del } 0 \text { al } 300 \\
2004 \text { Plaza La Roche } \\
2006 \text { Plaza San Martín } \\
2011 \text { Calle Almirante } \\
\text { Brown (entre San Martín } \\
\text { y } 9 \text { de Julio) } \\
2015 \text { Áreas entre Carlos } \\
\text { Casares y 2. }{ }^{\text {a Rivadavia }} \\
\text { calle Timbúes (Castelar) } \\
\text { 2016 Firma de un nuevo } \\
\text { convenio para intervenir } \\
\text { en otros centros comer- } \\
\text { ciales del municipio }\end{array}$ & $\begin{array}{l}\text { Proyecto para } \\
\text { el Área Central } \\
\text { de Morón } \\
(\text { ACM }) \\
\text { Plan de Desa- } \\
\text { rrollo Estraté- } \\
\text { gico 2020 } \\
(2005) \\
\text { Plan de CCCA } \\
\text { para otras loca- } \\
\text { lidades: } \\
\text { Castelar, } \\
\text { Haedo }\end{array}$ & $\begin{array}{l}\text { Traslado } \\
\text { del Club } \\
\text { Deportivo } \\
\text { Morón y } \\
\text { construc- } \\
\text { ción de } \\
\text { un polo } \\
\text { comercial y } \\
\text { recreativo }\end{array}$ \\
\hline $\begin{array}{l}\text { Localidad: } \\
\text { Don Torcua- } \\
\text { to (Tigre) } \\
\text { CCA Tigre } \\
2009\end{array}$ & $\begin{array}{l}\text { Centro comer- } \\
\text { cial de Almi- } \\
\text { rante Brown, el } \\
\text { Triunvirato, el } \\
\text { de la Ruta } 202, \\
\text { Riobamba y Los } \\
\text { Pinos } \\
\text { Total: } 8 \text { cuadras }\end{array}$ & $\begin{array}{l}\text { Municipio de Ti- } \\
\text { gre; Cámara el Ta- } \\
\text { lar Industria, Co- } \\
\text { mercio, Profesio- } \\
\text { nales y Servicios; } \\
\text { Cámara Comercial } \\
\text { e Industrial de } \\
\text { Tigre; Cámara } \\
\text { de Comercio de } \\
\text { Benavídez; Cáma- } \\
\text { ra de Comercio e } \\
\text { Industria de Don } \\
\text { Torcuato; Cámara } \\
\text { de Industria y Co- } \\
\text { mercio de General } \\
\text { Pacheco y Cámara } \\
\text { de Industria y Co- } \\
\text { mercio de Ricardo } \\
\text { Rojas. } \\
\text { Financiación: Mu- } \\
\text { nicipio }\end{array}$ & $\begin{array}{l}\text { Generar las condi- } \\
\text { ciones para que los } \\
\text { centros comerciales } \\
\text { de Tigre luzcan en } \\
\text { buen estado y brin- } \\
\text { den a los vecinos las } \\
\text { condiciones necesa- } \\
\text { rias para circular y } \\
\text { realizar sus compras } \\
\text { diarias }\end{array}$ & $\begin{array}{l}\text { Estética unificada: cambio } \\
\text { de materialidad de las } \\
\text { veredas, farolas, palmeras, } \\
\text { rampas para discapacitados, } \\
\text { mobiliario urbano como } \\
\text { bancos, bicicleteros. Entu- } \\
\text { bamiento para que no haya } \\
\text { agua en los cordones. Re- } \\
\text { ordenamiento del tránsito, } \\
\text { estacionameintos, nuevos } \\
\text { nodos de acceso }\end{array}$ & $\begin{array}{l}2011 \text { Calle Almirante } \\
\text { Brown, entre Ruta } 202 \text { y } \\
\text { Av. del Trabajo } \\
2013 \text { Calle Almiran- } \\
\text { te Brown, entre Ruta } \\
202 \text { y Av. del Trabajo/ } \\
\text { Riobamba entre Alvear } \\
\text { y Chile } \\
\text { 2015 Calle Campos, } \\
\text { entre Reconquista y } \\
\text { Estrada }\end{array}$ & $\begin{array}{l}\text { Plan de CCCA } \\
\text { para otras loca- } \\
\text { lidades: } \\
\text { Tigre centro } \\
\text { (sin informa- } \\
\text { ción) } \\
\text { El Talar (2015) } \\
\text { Pacheco } \\
(2013) \\
\text { Los Troncos } \\
(2013) \\
\text { Ricardo Rojas } \\
(2011) \\
\text { Benavídez } \\
(2009)\end{array}$ & $\begin{array}{l}\text { Nuevo } \\
\text { polidepor- } \\
\text { tivo a } 200 \\
\text { metros del } \\
\text { centro }\end{array}$ \\
\hline
\end{tabular}




\begin{tabular}{|c|c|c|c|c|c|c|c|}
\hline $\begin{array}{l}\text { Ubicación/ } \\
\text { Nombre } \\
\text { y año del } \\
\text { acuerdo }\end{array}$ & Área & $\begin{array}{c}\text { Agentes } \\
\text { intervinientes }\end{array}$ & Objetivos & Tareas a desarrollar & $\begin{array}{l}\text { Fecha y grado } \\
\text { de realización }\end{array}$ & $\begin{array}{l}\text { Instrumentos } \\
\text { urbanísticos } \\
\text { asociados }\end{array}$ & $\begin{array}{c}\text { Otras ope- } \\
\text { raciones en } \\
\text { el centro }\end{array}$ \\
\hline $\begin{array}{l}\text { Localidad: } \\
\text { San Isidro } \\
\text { (San Isidro) } \\
\text { Comer- } \\
\text { cio a Cielo } \\
\text { Abierto } \\
2011\end{array}$ & $\begin{array}{l}\text { Calle Belgrano, } \\
\text { entre Centena- } \\
\text { rio y las Cinco } \\
\text { Esquinas, y su } \\
\text { continuación } \\
\text { por calle } 9 \text { de } \\
\text { Julio hasta Li- } \\
\text { bertador } \\
\text { Total: } 10 \text { cua- } \\
\text { dras }\end{array}$ & $\begin{array}{l}\text { Municipalidad de } \\
\text { San Isidro; Cámara } \\
\text { de Comercio e } \\
\text { Industria del Par- } \\
\text { tido de San Isidro; } \\
\text { Colegio de Arqui- } \\
\text { tectos Distrito IV; } \\
\text { CAME } \\
\text { Financiación: no } \\
\text { especifica }\end{array}$ & $\begin{array}{l}\text { Revalorización del } \\
\text { área central, que a } \\
\text { su vez redundará en } \\
\text { la promoción de la } \\
\text { actividad comer- } \\
\text { cial y la atracción } \\
\text { turística }\end{array}$ & $\begin{array}{l}\text { La propuesta apuntó a resol- } \\
\text { ver los déficits encontrados } \\
\text { en las áreas comerciales de } \\
\text { mayor densidad y carencia } \\
\text { de árboles, devolviéndoles la } \\
\text { presencia vegetal y los espa- } \\
\text { cios amplios para el peatón: } \\
\\
\text { - Peatonalización de calles } \\
\text { - Sistematización de los } \\
\text { recorridos a patir de en- } \\
\text { sanchamiento de veredas, } \\
\text { cambio de materialidad, } \\
\text { nuevos equipamientos } \\
\text { - Recuperación de la iden- } \\
\text { tidad medioambiental de } \\
\text { San Isidro a través de la } \\
\text { introducción de más espa- } \\
\text { cios verdes } \\
\text { - Nuevos estacionamientos, } \\
\text { mejoras en la conectividad } \\
\text { y accesibilidad a las vías } \\
\text { principales }\end{array}$ & $\begin{array}{l}2013 \text { Concurso de Ideas } \\
\text { no vinculante convoca- } \\
\text { do por la Municipalidad } \\
\text { para reestructurar el } \\
\text { Centro Comercial de } \\
\text { San Isidro / Resultados } \\
\text { del Concurso de Ideas } \\
\text { no vinculante convoca- } \\
\text { do por la Municipalidad } \\
\text { para reestructurar el } \\
\text { Centro Comercial de } \\
\text { San Isidro } \\
\text { 2014 Primera etapa: } \\
\text { intervención urbanística } \\
\text { en las calles } 9 \text { de Julio, } \\
\text { Belgrano y Acassuso }\end{array}$ & $\begin{array}{l}\text { No se encontró } \\
\text { información }\end{array}$ & $\begin{array}{l}\text { No se } \\
\text { encontró } \\
\text { informa- } \\
\text { ción }\end{array}$ \\
\hline
\end{tabular}




\begin{tabular}{|c|c|c|c|c|c|c|c|}
\hline $\begin{array}{l}\text { Ubicación / } \\
\text { Nombre } \\
\text { y año del } \\
\text { acuerdo }\end{array}$ & Área & $\begin{array}{c}\text { Agentes } \\
\text { intervinientes }\end{array}$ & Objetivos & Tareas a desarrollar & $\begin{array}{l}\text { Fecha y grado } \\
\text { de realización }\end{array}$ & $\begin{array}{l}\text { Instrumentos } \\
\text { urbanísticos } \\
\text { asociados }\end{array}$ & $\begin{array}{l}\text { Otras ope- } \\
\text { raciones en } \\
\text { el centro }\end{array}$ \\
\hline $\begin{array}{l}\text { Localidad: } \\
\text { San Miguel } \\
\text { (San Mi- } \\
\text { guel) } \\
\text { Paseo San } \\
\text { Miguel } \\
2011\end{array}$ & $\begin{array}{l}\text { Área compren- } \\
\text { dida entre las } \\
\text { calles Sarmien- } \\
\text { to, Conesa, } \\
\text { D'Elía y Roca. } \\
\text { Actualmente de- } \\
\text { sarrollado sobre } \\
\text { Av. Perón } \\
\text { Total: } 10 \text { cua- } \\
\text { dras }\end{array}$ & $\begin{array}{l}\text { Municipio y la Cá- } \\
\text { mara de Comercio } \\
\text { e Industria local, a } \\
\text { través de los cuales } \\
\text { se crea el Consor- } \\
\text { cio Asociativo "Pa- } \\
\text { seo San Miguel" } \\
\text { Financiación: no } \\
\text { especifica }\end{array}$ & $\begin{array}{l}\text { Ser competitivos } \\
\text { en un escenario co- } \\
\text { mercial cambiante, } \\
\text { especialmente ante } \\
\text { la incipiente prefe- } \\
\text { rencia del público } \\
\text { por las grandes } \\
\text { superficies e hiper- } \\
\text { mercados }\end{array}$ & $\begin{array}{l}\text { Ensanchamiento de vere- } \\
\text { das, incorporación de ban- } \\
\text { cos, luminarias, estaciona- } \\
\text { mientos para bicicletas, ces- } \\
\text { tos de basura y rampas para } \\
\text { personas con movilidad } \\
\text { reducida. Soterramiento de } \\
\text { cables. Reordenamiento del } \\
\text { tránsito vehicular, nuevos } \\
\text { refugios de colectivos }\end{array}$ & $\begin{array}{l}2011 \text { Remodelación ca- } \\
\text { lle Sarmiento entre Roca } \\
\text { y Conesa } \\
2013 \text { Aguas danzantes } \\
\text { en Plaza Carretas / Ci- } \\
\text { clo "Esquinas culturales" } \\
\text { sobre Av. Perón } \\
2015 \text { Remodelación } \\
\text { calles Sarmiento, Roca } \\
\text { y Conesa y calles Italia y } \\
\text { Tribulato } \\
\text { 2016 Estacionamiento } \\
\text { medido en el "Paseo San } \\
\text { Miguel" }\end{array}$ & $\begin{array}{l}\text { Plan "Corre- } \\
\text { dor Aeróbico } \\
\text { Municipal" } \\
\text { de Avenida } \\
\text { Francia }\end{array}$ & $\begin{array}{l}\text { No se } \\
\text { encontró } \\
\text { informa- } \\
\text { ción }\end{array}$ \\
\hline $\begin{array}{l}\text { Localidad: } \\
\text { Lomas de } \\
\text { Zamora } \\
\text { (Lomas de } \\
\text { Zamora) } \\
\text { CCA Lomas } \\
\text { de Zamora } \\
2012 \\
2016\end{array}$ & $\begin{array}{l}\text { Peatonal La- } \\
\text { prida, entre Av. } \\
\text { Meeks y Av. Hi- } \\
\text { pólito Yrigoyen } \\
\text { Total: } 3 \text { cuadras }\end{array}$ & $\begin{array}{l}\text { Municipalidad de } \\
\text { Lomas de Zamora; } \\
\text { Cámara Regional } \\
\text { de Comercio e In- } \\
\text { dustria de Lomas } \\
\text { de Zamora } \\
\text { Financiación: fon- } \\
\text { dos del plan "Más } \\
\text { Cerca", impulsado } \\
\text { por el Gobierno de } \\
\text { la Nación }\end{array}$ & $\begin{array}{l}\text { Embellecer y dotar } \\
\text { de infraestructura a } \\
\text { la peatonal Laprida, } \\
\text { principal arteria } \\
\text { comercial de la } \\
\text { ciudad }\end{array}$ & $\begin{array}{l}\text { Reducción de la conta- } \\
\text { minación visual para que } \\
\text { la peatonal esté limpia, } \\
\text { incorporación de nuevas } \\
\text { luminarias y áreas de des- } \\
\text { canso, además de trabajos } \\
\text { de bacheo y pavimentación }\end{array}$ & $\begin{array}{l}2013 \text { Peatonal Laprida } \\
\text { (entre Av. Meeks y Av. } \\
\text { Hipólito Yrigoyen) } \\
\text { 2016 Firma de un nuevo } \\
\text { acuerdo entre la Cámara } \\
\text { de Comercio e Industria } \\
\text { de Lomas de Zamora, } \\
\text { la Federación Econó- } \\
\text { mica de Buenos Aires } \\
\text { (FEBA), CAME y el } \\
\text { Intendente local, Martín } \\
\text { Insaurralde }\end{array}$ & $\begin{array}{l}\text { No se encontró } \\
\text { información }\end{array}$ & $\begin{array}{l}\text { Obras } \\
\text { en calle } \\
\text { Boedo }\end{array}$ \\
\hline $\begin{array}{l}\text { Localidad: } \\
\text { Munro } \\
\text { (Vicente } \\
\text { López) } \\
\text { CCA Munro } \\
2014\end{array}$ & $\begin{array}{l}\text { Av. Mitre, entre } \\
\text { calles Vélez Sar- } \\
\text { field y Marconi } \\
\text { Total: } 2 \text { cuadras }\end{array}$ & $\begin{array}{l}\text { Cámara Empresa- } \\
\text { ria, la Municipa- } \\
\text { lidad de Vicente } \\
\text { López y CAME, } \\
\text { a través del PRO- } \\
\text { COM } \\
\text { Financiación: no } \\
\text { especifica }\end{array}$ & $\begin{array}{l}\text { Renovar de manera } \\
\text { integral el centro } \\
\text { comercial tradicio- } \\
\text { nal, buscando una } \\
\text { mejor experiencia } \\
\text { para el vecino en el } \\
\text { paseo de compras, } \\
\text { al mismo tiempo } \\
\text { que los comercian- } \\
\text { tes aumentan su } \\
\text { actividad y el desa- } \\
\text { rrollo de esas zonas } \\
\text { se ve favorecido }\end{array}$ & $\begin{array}{l}\text { Nueva iluminación, reno- } \\
\text { vación de veredas, nueva } \\
\text { señalización y mobiliario, } \\
\text { limpieza y recolección de } \\
\text { residuos, poda, mejo- } \\
\text { ramiento de cenefas y } \\
\text { cartelería, ordenamiento de } \\
\text { tránsito (incorporación del } \\
\text { estacionamiento tarifado), } \\
\text { demarcación peatonal, } \\
\text { creación de dársenas para } \\
\text { estacionamiento, descar- } \\
\text { gas de mercadería, taxis } \\
\text { y colectivos, cámaras de } \\
\text { seguridad }\end{array}$ & $\begin{array}{l}\text { 2014-2015 Av. Mitre } \\
\text { desde Vélez Sarsfield } \\
\text { hasta Marconi }\end{array}$ & $\begin{array}{l}\text { Plan de CCCA } \\
\text { para otras loca- } \\
\text { lidades: } \\
\text { Bajo de Vicen- } \\
\text { te López } \\
\text { La Lucila } \\
\text { Villa Martinelli }\end{array}$ & $\begin{array}{l}\text { Centro } \\
\text { Comercial } \\
\text { del Bajo } \\
\text { de Vicente } \\
\text { López }\end{array}$ \\
\hline
\end{tabular}




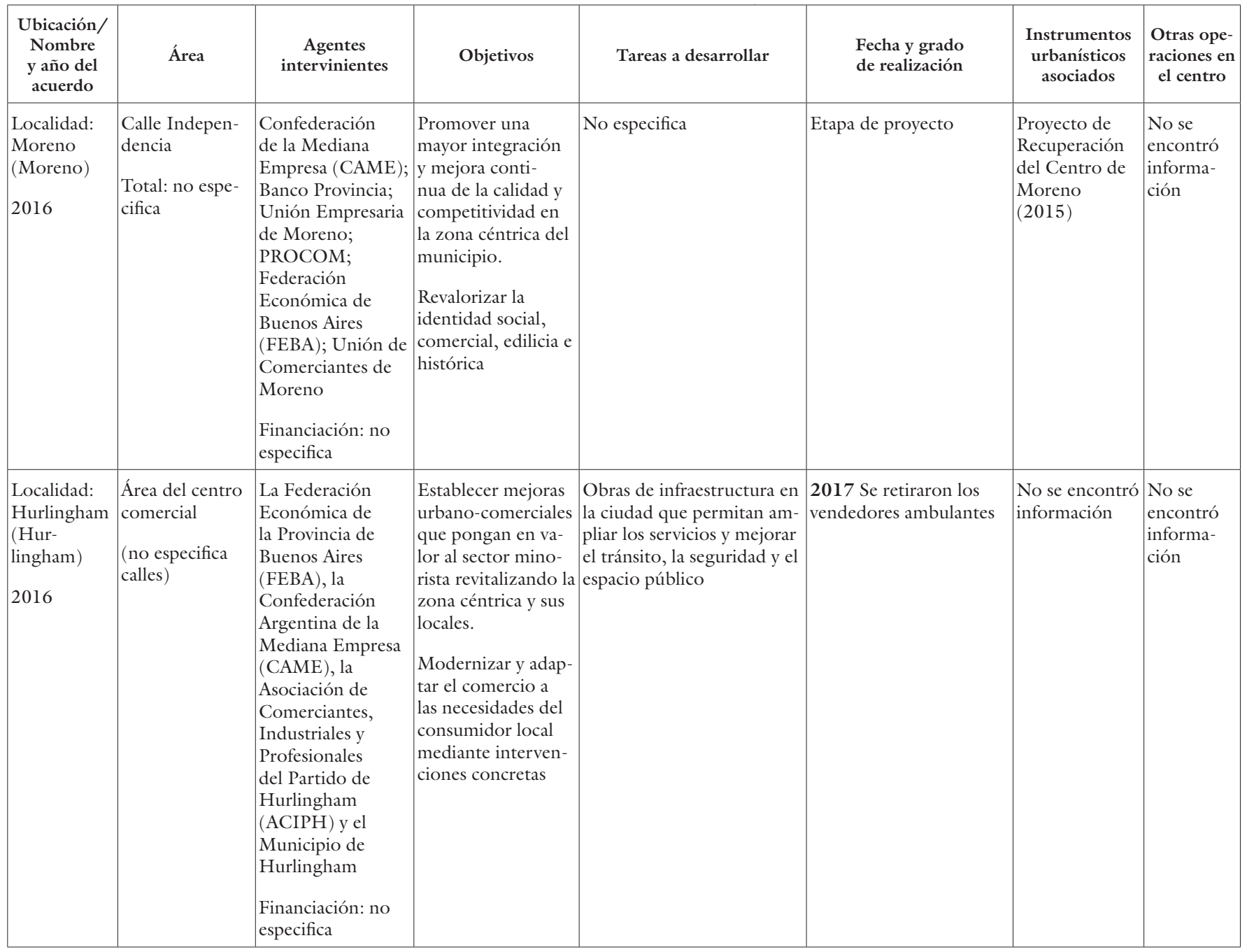

\section{territarias 38}




\begin{tabular}{|c|c|c|c|c|c|c|c|}
\hline $\begin{array}{c}\text { Ubicación/ } \\
\text { Nombre } \\
\text { y año del } \\
\text { acuerdo }\end{array}$ & Área & $\begin{array}{c}\text { Agentes } \\
\text { intervinientes }\end{array}$ & Objetivos & Tareas a desarrollar & $\begin{array}{l}\text { Fecha y grado } \\
\text { de realización }\end{array}$ & $\begin{array}{l}\text { Instrumentos } \\
\text { urbanísticos } \\
\text { asociados }\end{array}$ & $\begin{array}{l}\text { Otras ope- } \\
\text { raciones en } \\
\text { el centro }\end{array}$ \\
\hline $\begin{array}{l}\text { Localidad: } \\
\text { Loma Her- } \\
\text { mosa / El } \\
\text { Libertador } \\
\text { (Tres de } \\
\text { Febrero) } \\
2016\end{array}$ & $\begin{array}{l}\text { Calle } 1 .^{\circ} \text { de } \\
\text { Mayo entre Río } \\
\text { Cuba y Ruta } 8 \\
\text { Total: } 2 \text { cuadras }\end{array}$ & $\begin{array}{l}\text { Municipio; Cáma- } \\
\text { ra de Comercio } \\
\text { e Industria local; } \\
\text { Confederación } \\
\text { Argentina de la } \\
\text { Mediana Empresa } \\
\text { (CAME) y Fede- } \\
\text { ración Económica } \\
\text { de la Provincia } \\
\text { de Buenos Aires } \\
\text { (FEBA) } \\
\text { Financiación: Mu- } \\
\text { nicipio }\end{array}$ & $\begin{array}{l}\text { Poner en valor del } \\
\text { centro comercial a } \\
\text { cielo abierto de la } \\
\text { calle } 1 .^{\circ} \text { de Mayo y } \\
\text { ruta } 8 . \\
\text { Potenciar el comer- } \\
\text { cio y el encuentro } \\
\text { entre los vecinos }\end{array}$ & $\begin{array}{l}\text { Ensanchamiento de la cal- } \\
\text { zada, nuevas veredas, ilumi- } \\
\text { nación y mobiliario (bancos } \\
\text { y cestos de residuos). Cons- } \\
\text { trucción de sumideros y el } \\
\text { ordenamiento publicitario }\end{array}$ & Etapa de proyecto & $\begin{array}{l}\text { Plan de CCCA } \\
\text { para otras loca- } \\
\text { lidades: Plaza } \\
\text { Plate, Ciudad } \\
\text { Jardín, El Palo- } \\
\text { mar, Caseros, } \\
\text { Martín Coro- } \\
\text { nado, Pablo } \\
\text { Podestá, Sáenz } \\
\text { Peña, Villa } \\
\text { Bosch, Villa } \\
\text { Raffo, Santos } \\
\text { Lugares, Ciu- } \\
\text { dadela }\end{array}$ & $\begin{array}{l}\text { No se } \\
\text { encontró } \\
\text { informa- } \\
\text { ción }\end{array}$ \\
\hline
\end{tabular}

Fuente: elaboración propia.

Además, en nueve de las diez localidades seleccionadas se ha intervenido en un solo sector urbano, siendo Don Torcuato la única que cuenta con múltiples intervenciones, bajo una idea sistémica o de policentralidades, lo cual se replica a nivel de partido (las acciones no se concentran solo en la ciudad cabecera, sino también en otras cinco localidades). Algo similar ocurre en el partido de Tres de Febrero que cuenta con once estudios o propuestas de intervención, tres de ellas en la localidad de El Palomar.

El redibujo de estas operaciones denota, asimismo, las limitaciones que supone su formulación en el ámbito local, debiendo circunscribirse al ejido municipal. Esta situación muchas veces no se condice con el desarrollo de las centralidades en el Св, que por su propia fisonomía continua tienden a superar los límites político-adminis- trativos. Un ejemplo de ello es el caso de San Fernando, cuya intervención culmina exactamente en el límite con el partido de Tigre, junto a una gran superficie comercial. El CCCA de San Miguel — nodo que atrae a municipios vecinos como José C. Paz y Malvinas Argentinas- se presenta como la única excepción a los otros casos, excediendo su área de intervención - aunque dentro del mismo partido- sobre la localidad contigua de Muñiz. La concentración de oferta de comercios y servicios en este sector probablemente está asociada a que, hasta el año 1995, San Miguel fue cabecera del antiguo partido General Sarmiento, actualmente desmembrado en José C. Paz y Malvinas Argentinas ${ }^{17}$. En este sentido, la historia de las subdivisiones municipales (por ejemplo, Hurlingham como parte de Morón, o Tres de Febrero, antes perteneciente al partido de San Martín)
${ }^{17}$ Para mayor información acerca del proceso de densificación y verticalización residencial, así como de las intervenciones públicas en el Microcentro de San Miguel, véase Muñoz, 2014.

territarios 38 29 
${ }_{18}$ Sin embargo, existe la figura del gerente urbano en CABA y en provincias del interior del pais.

\section{territarias 38}

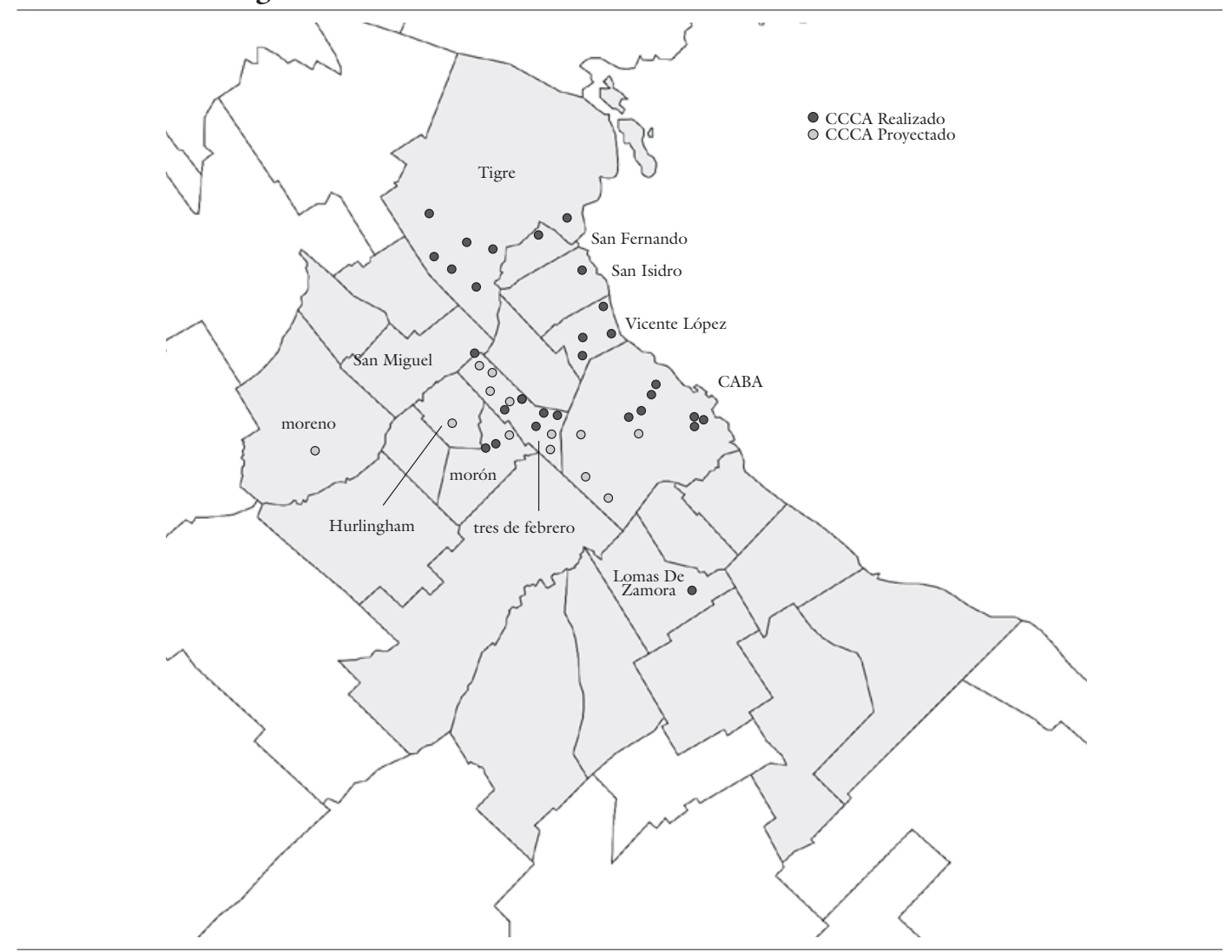

Fuente: Elaboración propia.

se relaciona con el mayor o menor peso — así como con el carácter múltiple- de las centralidades objeto de análisis.

Por otro lado, la información recabada arroja que estos proyectos, por razones económicas y/o de coyuntura política, se desarrollan en diferentes etapas, lo que implica, muchas veces, el transcurso de varios años para su completa ejecución. Como los convenios firmados supeditan el financiamiento de los proyectos a los gobiernos locales, sin una entidad independiente para la gerencia del proyecto de $\mathrm{CCCA}^{18}$, esto se presenta a veces $\mathrm{CO}^{-}$ mo una dificultad al momento de generar continuidad en las políticas de intervención. Sin embargo, esto no ha impedido que localidades como San Fernando hayan concretado completamente los objetivos establecidos en su convenio, y que incluso decidieran extender el área de intervención. En este sentido, y tal como 
se mencionó, el CCCA de San Miguel se presenta como un caso de gestión singular ya que es el único del cual surgió un ente especifico de control: el "Consorcio Asociativo Paseo San Miguel”, responsable del mantenimiento y de la promoción del centro e, incluso, de fijar una cuota para los comercios del área involucrada, lo que supone un punto de contacto con los casos de referencia estudiados ${ }^{19}$.

En relación con la vinculación con otros instrumentos urbanísticos, si bien algunas intervenciones de CCCA se inscriben en el marco de planes urbanos a escala municipal (por ejemplo, Morón, San Fernando, Moreno), no suelen aparecer integradas con el resto de políticas públicas sectoriales - en materia de movilidad, manejo de residuos, vivienda social, e incluso de espacio público-; así como también se observan escasas articulaciones con otros sectores de intervención urbana del mismo u otro municipio. Por ejemplo, en relación con las políticas de transporte, se puede mencionar el caso del centro de Lomas de Zamora. En esta localidad, muy convocante durante los fines de semana, debido especialmente a la revitalización del comercio de calle en la zona apodada "Las Lomitas" - contigua al centro tradicional- y a las tareas de mejora de la peatonal Laprida, la accesibilidad desde el transporte público y privado, la problemática del estacionamiento en playas o en vías públicas, el reordenamiento de las líneas de buses y el acondicionamiento de paradas, etc., quedaron relegados frente a la búsqueda de una "imagen" unitaria del centro como factor de atracción comercial (Vecslir et al., 2017) ${ }^{20}$.

Como contrapunto a ese ejemplo, el CCCA de Morón es de los pocos casos que se integra en un proyecto para el fortalecimiento del área central, basado en intervenciones en el espacio público como estructurante de sus áreas funcionales y simbólicas (institucional, cultural y judicial), y de los ejes comerciales que las vinculan. Si bien los proyectos CCCA y Plaza La Roche tienen su origen a comienzos de la década de los años 2000, cuando todavía el municipio no contaba con un marco amplio de planificación, en el año 2005 se presentó el Plan Estratégico 2020, en el que ambas intervenciones aparecen vinculadas a otras actuaciones e inscritas dentro del proyecto Área Central de Morón, y a este último dentro del programa Áreas Centrales (Bustos, Colella \& Da Representacao, 2010).

Aunque en general tampoco se vislumbran estudios o planes que pongan en relación los CCCA con políticas territoriales más bastas, existen algunos convenios recientes como el "Plan D" 21 , que muestran la voluntad asociativa de municipios, en este caso, de la zona norte (Vicente López, San Isidro, San Fernando y Tigre), con el objetivo de coordinar políticas y acciones gubernamentales para reforzar la potencialidad económica y social de un sector de la región metropolitana, superando los límites municipales.

Particularmente, los objetivos planteados desde los diferentes convenios se orientan a generar mejores condiciones de
${ }^{19}$ En diciembre del 2012 se firmó entre la Municipalidad de San Miguel y la Cámara de Comercio local una carta de intención para trabajar en conjunto en el desarrollo de este, extendiendo el radio de influencia del Paseo San Miguel más allá de la avenida Perón hasta Maestro D'Elía, Paunero y Sarmiento entre J. A. Roca y Conesa (Muñoz, 2014).

${ }^{20}$ En el trabajo citado, tanto en las opiniones de las personas encuestadas en calle, como en las entrevistas realizadas a los responsables de estas politicas en Lomas de Zamora, el tema de la movilidad fue señalado como una problemática pendiente, reflejada en la poca frecuencia de algunas lineas de transporte público, en la dificultad de acceso al centro y en el colapso de tránsito y la falta de estacionamientos durante los fines de semana, entre otros. También se mencionaron problemas vinculados a la recolección de basura, e insuficiencia de infraestructura (especialmente energética) frente al desarrollo comercial y los nuevos edificios en altura.

${ }^{21}$ Para mayor información sobre el "Plan D" véase www.plande.org.ar

territarias 38 
${ }^{22}$ Como ejemplo, la CAME cita el municipio de Vicente López, donde la "saladita" ubicada en las calles Vélez Sarsfield y Av. Mitre se regularizó, aunque advierte que esto solo significa "un leve avance para el distrito", y que igualmente la Av. Mitre sigue invadida por vendedores ambulantes. Disponible en: http://www. redcame.org.ar/contenidos/comunicado/CrecioLa-Venta-Ilegal-En-LaArgentina.994.html

\section{territarias 38}

competitividad para los comercios involucrados, poniendo en valor la identidad del sector a partir de determinadas acciones de renovación o reacondicionamiento del área urbana (figuras 5 y 6). Sin embargo, aunque el argumento de la valorización identitaria supondría acciones específicas que respondan a la idiosincrasia de cada localidad, lo cierto es que son muy semejantes en todos los casos estudiados. Podemos ordenar estas acciones en tres categorías:

- Infraestructura: ensanchamiento de veredas y/o igualación de su nivel con el de la calle, nuevas dársenas para estacionamiento, soterramiento del cableado eléctrico y nuevos desagües pluviales.

- Equipamiento urbano y materialidad: incorporación de nuevos pavimentos, luminarias, cestos de residuos y espacios de permanencia; preservación o propuesta de arbolado urbano; pintado de sendas peatonales y carriles vehiculares.

- Señalética y cartelería comercial: reemplazo de la señalética existente por una con estética gráfica unificada que facilite la identificación del centro, su localización desde las arterias principales y la ubicación de locales y marcas; eliminación de la publicidad urbana (carteles bandera, marquesinas, pasacalles); alineación de las marquesinas y regulación de la cartelería comercial según las normativas municipales.

Se trata, en general, de tareas orientadas a eliminar la "contaminación visual" y a dar "identidad" al sector, lo cual responde a cuestiones estéticas más que funcionales. En este sentido, la propuesta del mismo tipo de intervenciones en los diferentes contextos analizados arroja algunos interrogantes: ¿cómo se relacionan las obras de mejora con el rescate identitario buscado? $\mathrm{E}$, incluso, ¿cuál es la identidad que quiere revalorizarse?

Para ejemplificar esta cuestión, podemos citar el caso de Munro. La emblemática Avenida Mitre supo ser conocida como "la meca del jean" entre los años setenta y ochenta, cuya concentración de outlets atraía a personas del territorio regional. Sin embargo, aunque desde los objetivos planteados para el convenio de CCCA se reconoce esta importante tradición comercial, no se explica su correlato con las tareas de renovación urbana que se van a desarrollar, ni cómo diferenciar el tratamiento de un corredor especializado de estas características respecto de un centro urbano histórico o institucional.

Por otro lado, iniciativas recientes como las de la localidad de Hurlingham concentraron sus primeras acciones en quitar la venta ambulante del sector, siendo su erradicación una de las políticas básicas impulsadas por la CAME. Bajo el lema de "recuperar la calle", se soslaya el significado social, económico e incluso simbólico que este tipo de comercio construye en el espacio urbano, acompañando - en el mejor de los casos- la propuesta de su relocalización en "ferias oficializadas" 22 con el fin de incorporar, paulatinamente, la venta ambulante al comercio formal. 
Figura 3. Localización de las intervenciones de CCCA por localidad

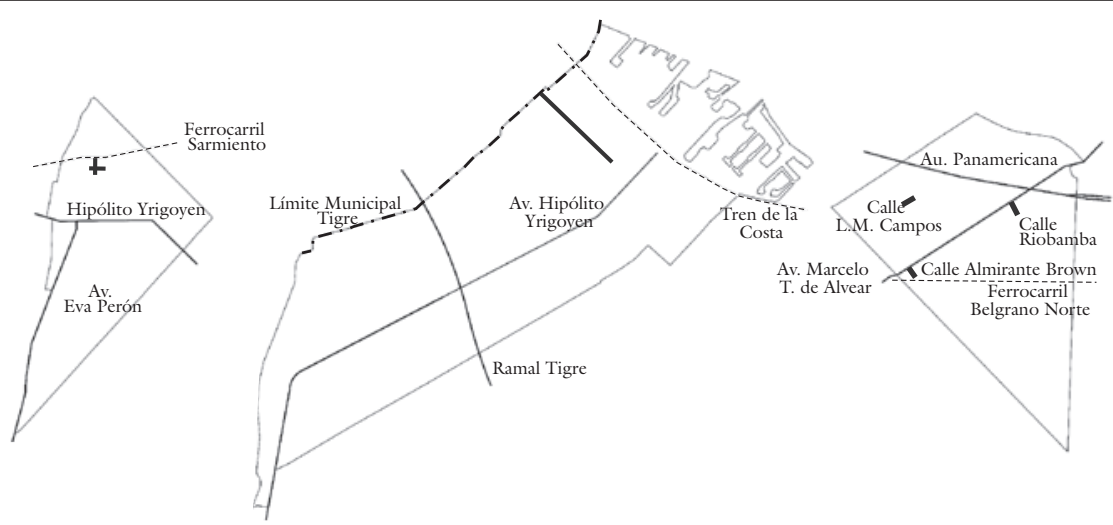

Morón

San Fernando

Don Torcuato
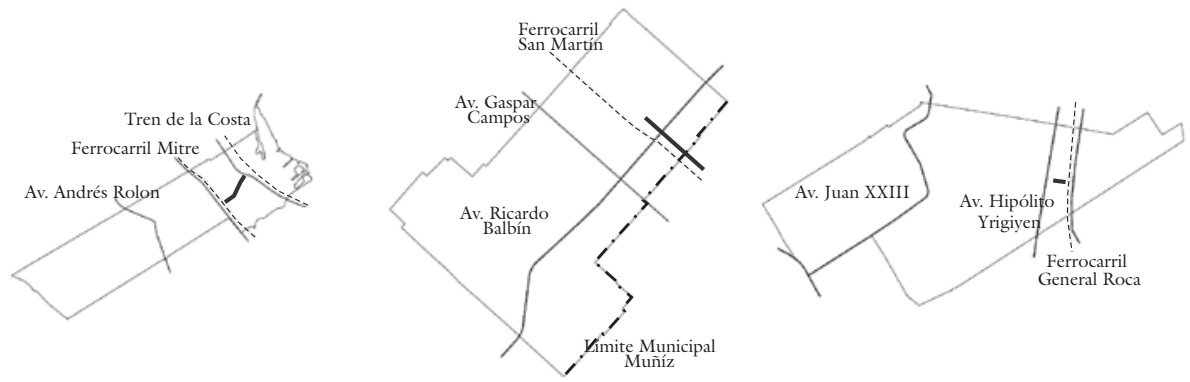

San Isidro

San Miguel

Lomas de Zamora
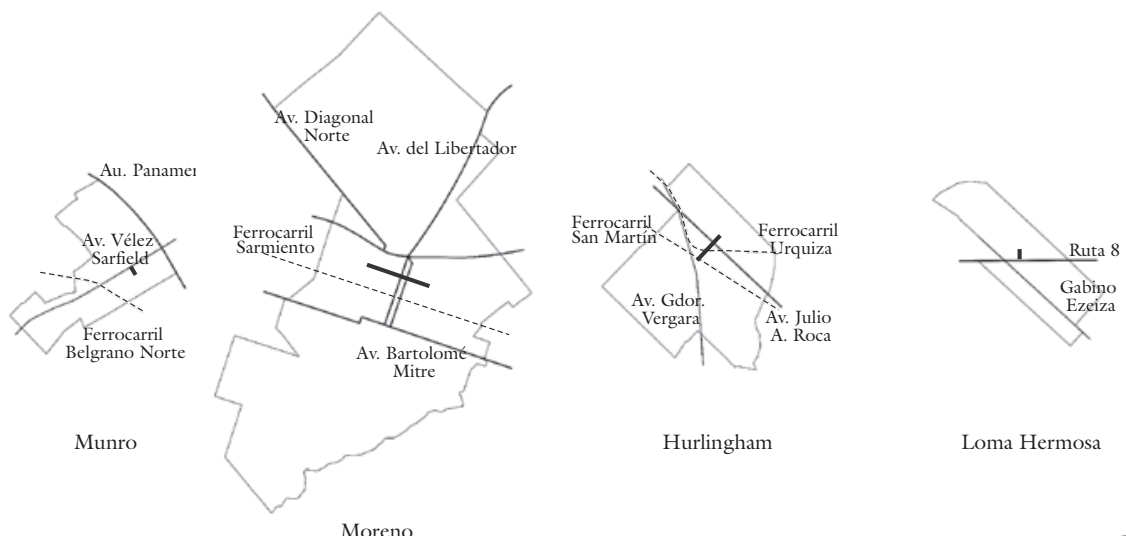

Hurlingham

Loma Hermosa

Moreno

$\underset{1000 \mathrm{~m} 3000 \mathrm{~m}}{ }$

Fuente: Elaboración propia.

territarios 38

Centros Comerciales a Cielo Abierto como política de renovación 
Figura 4. Detalle de las intervenciones de CCCA por localidad
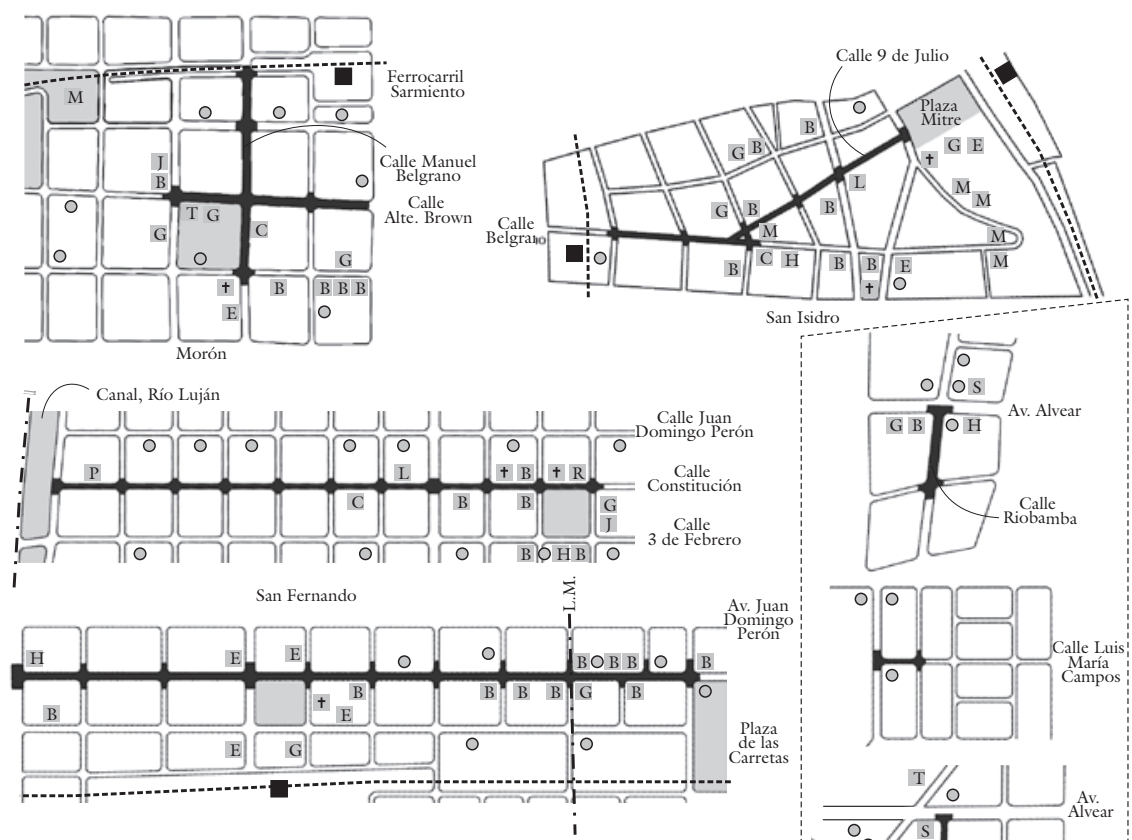

an Miguel
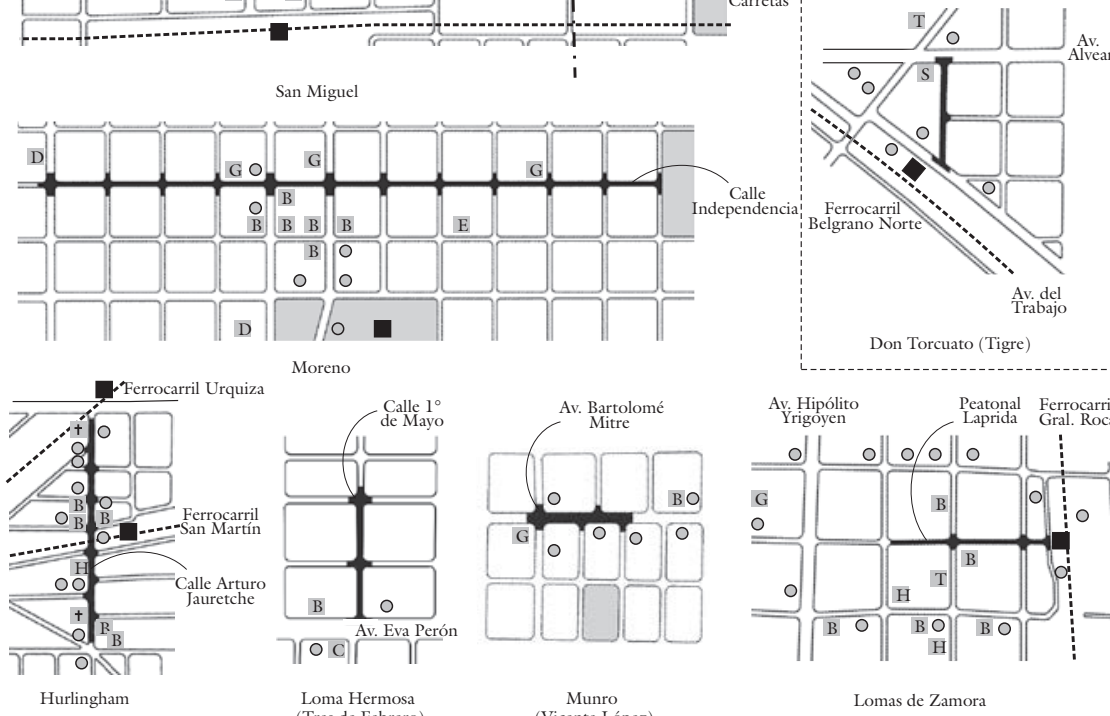

Moreno

territarias 38
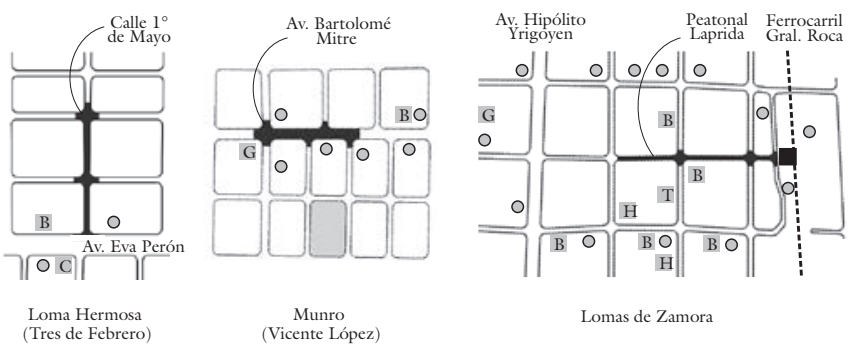

B Banco G Gubernamental L Biblioteca $\quad$ R Radio

\begin{tabular}{l|l|l|l}
\hline C Correo & H Salud & M Museo & S Estació \\
\hline E Escuela & J Juegos & P Policía/ Bomberos & T Teatro
\end{tabular}

+ Iglesia

O Parada bus

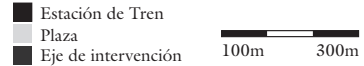

Fuente: Elaboración propia 
En el marco de esta discusión, cabe citar, por último, el caso de San Isidro, donde el proyecto ganador de un concurso de ideas para la renovación del centro histórico de la ciudad y, por tanto, de su área comercial, se propuso reforzar la identidad "verde", el equilibrio entre ciudad y naturaleza que caracteriza al municipio $^{23}$. Esta propuesta representa el único caso en el que se explicita qué valores urbanos - aunque limitados a los aspectos físicos- pretenden enfatizarse y a través de qué acciones. En ese ejemplo particular se buscan resolver los déficits encontrados en áreas de mayor densidad mediante una normativa de incorporación de vegetación que, combinada con la normativa publicitaria, defina incentivos y premios para direccionar la iniciativa privada. Se destaca, asimismo, como singularidad, la propuesta de estacionamientos subterráneos y de incorporación de vegetación autóctona, toldos verdes y luminaria tubular curvada en la urbanización del espacio público.

\section{Reflexiones finales}

La revisión de casos efectuada en este trabajo permite reflexionar, en primer lugar, acerca de las diferencias que plantean los modelos de CCCA estudiados como antecedentes y su utilización como política de renovación de las centralidades tradicionales en el $\mathrm{CB}$. Una de las más notorias es la ausencia de entes de gerenciamiento que, en contraposición a las experiencias españolas, compromete, en muchos casos, la continuidad de las políticas promovidas por los convenios. Debido a que el financiamiento y posterior responsabilidad de gestión recae casi exclusivamente en los gobiernos locales, estos quedan supeditados a los vaivenes económicos y a las voluntades políticas. Por otro lado, el declive que sufren los centros urbanos de referencia - especialmente en Estados Unidos- no es una situación análoga a la de los ejemplos locales que, tal como se expuso en este y anteriores trabajos (Vecslir \& Blanco, 2014; Ciccolella, Vecslir \& Baer, 2015), aun con signos de deterioro
${ }^{23}$ El Concurso Nacional de Ideas para la 'Renovación urbana del centro de San Isidro' fue convocado en el 2013 por el Colegio de Arquitectos de la Provincia de Buenos Aires (CAPBA), la Municipalidad de San Isidro, la Cámara de Comercio y la CAME.

Figura 5. Cuatro operaciones de CCCA en el espacio público: San Fernando, Morón, San Isidro y Lomas de Zamora
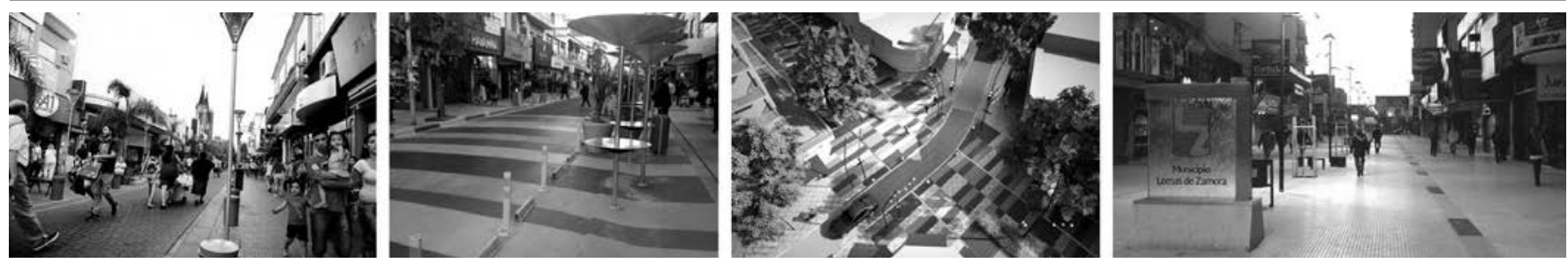

Fuente: Fotografías tomadas de http://quepasaweb.com.ar/la-calle-constitucion-de-san-fernando-seguira-como-peatonal-este-jueves-24/; http://redcame. org.ar/adjuntos/ANEXO\%20\%20CAME\%20en\%20la\%20Inanguracion\%20del\%0CCCA\%20Moron.pdf; http://www.plataformaarquitectura.cl/cl/02344342/primer-lugar-concurso-nacional-de-ideas-para-la-renovacion-urbana-del-area-centro-de-san-isidro-argentina; http://www.redcame.org.ar/ contenidos/circular/CAME-participo-de-la-inauguracion-de-la-peatonal-Laprida.4316.html 
ambiental, conservan gran dinamismo comercial o incluso se han revitalizado y extendido "vía mercado" junto a recientes procesos de verticalización residencial (por ejemplo, Lomas de Zamora, San Miguel, Tigre centro, Vicente López, etc.).

Asimismo, según Bustos, Colella \& Da Representacao (2010) se verifica una lógica de intervención común a todos los municipios del $\mathrm{CB}$ que asocia las acciones en el centro fundamentalmente al espacio público y al equipamiento, y en la periferia a la infraestructura y la vivienda social; esta dicotomía no parece comulgar con los objetivos de hibridez funcional e inclusión social de algunos antecedentes de los CCCA, así como tampoco parece corresponderse con las nuevas configuraciones metropolitanas de límites difusos.

Esto nos lleva a preguntarnos: ¡ंes entonces la motivación principal del CCCA configurarse en nuestro contexto como un instrumento en contra del shopping y de las "saladitas"? ¿O es más bien un instrumento que refuerza un tipo de centralidad específica (la tradicional) que beneficia a cierto grupo de actores y ejerce, por lo tanto, de manera análoga al shopping?

Al objetivo de revitalización de las "centralidades históricas", desarrolladas en torno a las estaciones ferroviarias como lugares de concentración institucional, del comercio cotidiano, de los servicios y del espacio público tradicional, los convenios de CCCA contraponen el surgimiento y la competencia de las "nuevas centralidades" periféricas, en forma de enclaves aislados del ocio y del consumo. Sin embargo, la existencia de corredores con gran dinamismo económico a lo largo de rutas, ejes ferroviarios, avenidas y demás formas de concentración lineal, que atraviesan uno o varios partidos del $\mathrm{CB}$, nos habla de otras configuraciones de la centralidad, no previstas por los CCCA — ni en general por los instrumentos de planificación vigentes(Vecslir \& Elimbaum, 2016). Las intervenciones analizadas continúan concibiendo la centralidad de la manera tradicional, y se desarrollan, en casi todos los casos, dentro de los límites político-administrativos, ignorando la continuidad física y funcional

Figura 6. Cuatro operaciones de CCCA en el espacio público: Munro, Don Torcuato, Bajo de Vicente López y San Miguel
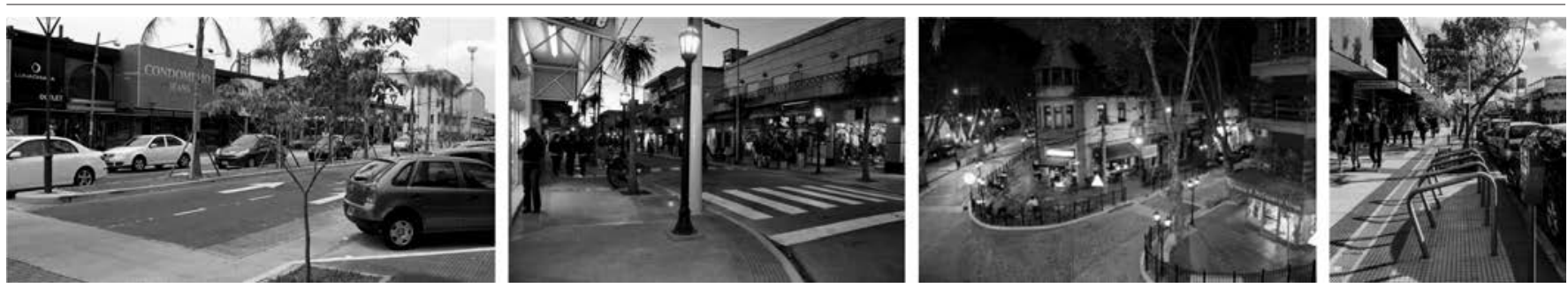

Fuente: Fotografías tomadas de http://www.vicentelopez.gov.ar/noticias/el-centro-comercial-munro-ya-luce-renovado; https://www.facebook.com/ notes/municipio-de-tigre/massa-inaugur\%C3\%B3-un-renovado-centro-comercial-en-don-torcuato/10150603210875307/; http://www.vicentelopez.gov. ar/noticias/el-centro-comercial-del-bajo-de-vicente-lopez-luce-renovado-y-puesto-en-valor-2; Confederación Argentina de la Mediana Empresa, 2015. 
que muchos ejes comerciales presentan entre localidades del mismo y de otros municipios de la región metropolitana.

Claro que considerar estas centralidades lineales supondría cierta sofisticación de los instrumentos urbanísticos empleados, al tratarse de proyectos de carácter supramunicipal. Sin embargo, como también se ha analizado, estos instrumentos no solo son posibles de ser materializados, sino que de hecho se están intentando llevar a cabo desde los municipios del corredor norte a través del ya mencionado "Plan D". Este tipo de alianzas territoriales permitiría enmarcar las operaciones de CCCA en políticas más amplias de movilidad y accesibilidad desde el transporte público, así como también abriría la discusión en torno de las competencias y complementariedades del sistema de centralidades a escala de toda la región metropolitana.

Finalmente, el trabajo realizado deja ver una serie de contradicciones entre los objetivos de rescate identitario propuestos y las acciones que efectivamente se llevan a cabo para conseguirlos. Como se planteaba en el punto anterior, en la mayoría de los casos analizados no existe una reflexión sobre los rasgos característicos de cada localidad ni la identidad que quiere valorizarse.

Desde esta perspectiva, la venta ambulante - una forma de comercialización muy extendida en nuestra región metropolitana- es vista sin excepción como una amenaza para el comercio de calle. Se aplica en general una política de expulsión
- o, en el mejor de los casos, de reubicación fuera de los ejes comerciales- que se manifiesta incluso con más fuerza en la ciudad capital, donde en el último tiempo se han establecido importantes medidas de desalojo de los manteros en diferentes barrios como Once o Retiro. Aunque su estudio específico escapa a los alcances del presente trabajo, el rol del comercio ambulante como parte de la idiosincrasia de muchos centros urbanos, la complementariedad de algunos productos comercializados y la repercusión para la animación peatonal que suponen, así como las escasas propuestas de relocalización en predios cerrados y aislados, llevan a cuestionarnos sobre los intereses que subyacen a estas políticas de mejoramiento urbano.

Por otro lado, se considera necesario tener en cuenta los efectos - aun incipientes-que la "estetización" del espacio urbano puede acarrear para las formas de comercio tradicional. El aumento de valor en la renta y la asistencia de un público con mayores ingresos económicos - consecuencias de estas acciones- podrían traer aparejado la progresiva boutiquización y el recambio del tipo de comercio local. Informes de CAME expresan que a medida que las ventas aumentan, al nuevo CCCA concurre población con niveles de ingresos más altos, a lo que se suma el encarecimiento en el valor de los inmuebles y consecuentemente de los alquileres.

En un reciente artículo publicado en la página web de FCCA se exponían los beneficios de las intervenciones de CCCA territarias 38 
en Barcelona y Nueva York: se comentaba que ahora "los clientes entran y salen de restaurantes, vinerías, salones de belleza y tiendas de ropa" y que esos resultados "confirman la necesidad impostergable de recuperar las calles para las personas. No sólo en beneficio del sector comercial, sino también para poner en valor las prácticas sociales que mantienen vivas nuestras ciudades" (Federación de Centros Comerciales a Cielo Abierto, Cascos Históricos y Centros Urbanos, 2016).

Estas cuestiones ponen de manifiesto el riesgo de la adopción de modelos de gestión desarrollados en otros contextos geográficos, sin ponderar sus diferencias con las de la realidad local. El principal problema de la transferencia de políticas sin una reformulación previa recae en las contradicciones que su aplicación produce en relación con los objetivos que se persiguen. Principalmente cómo se articula la cuestión identitaria (ciudadana y comercial) en las propuestas de renovación urbana.

Sin duda las acciones de mejoramiento de los centros urbanos dotan a sus comercios de herramientas para competir con otros formatos, generan lugares atractivos para el público visitante y dinamizan el mercado del suelo. Sin embargo, debemos preguntarnos si al mismo tiempo se están generando nuevos procesos y espacios de exclusión, semejantes a los promovidos por las superficies comerciales contra las que se quiere competir.

\section{Referencias}

Asociación Provincial de Empresarios de Comercio de Huelva (2000). I Congreso Nacional de Centros Comerciales Abiertos. La Trastienda, IV(4).

Bratos Martín, M. (2013). Business Improvement Districts: Una nueva forma de colaboración público-privada para la revitalización socioeconómica de áreas urbanas. Politica y Sociedad, 50(1), 269-304.

Bustos, W., Colella, V. \& Da Representacao, N. (2010). Los centros tradicionales en la agenda política. Intervenciones en el espacio público. VI Jornadas de Sociología de la UNLP. La Plata.

Confederación Argentina de la Mediana Empresa - CAME (2016). Centros Comerciales Abiertos. 15 años. 100 ciudades. Buenos Aires: Revista Comerciar, Edición especial.

Carrión, F. (Ed.) (2001). Centros históricos de América Latina y El Caribe. Quito: UNESCO-BID-FLACSO.

Carrión, F. (2005). La internacionalización de los centros históricos. Vivienda Popular, 16, 73-75.

Carrión, F. (2007). Financiamiento de los centros históricos de América Latina y El Caribe. Quito: FLACSO - Sede Ecuador; Lincoln Institute of Land Policy.

Ciccolella, P., Vecslir, L. \& Baer, L. (2015). Revitalización de subcentros metropolitanos. Buenos Aires entre la ciudad dispersa y la ciudad compacta. Contexto, Revista de la Facultad de Arquitectura 
de la Universidad Autónoma de Nuevo León, 11, 11-28.

Domingues, A. (2002). Metamorfoses do Centro: dinámicas de transformação da condição central. Textos de Mestrado, mimeo.

Federación de Centros Comerciales a Cielo Abierto, Cascos Históricos y Centros Urbanos - FCCA (2016). Los autos no hacen compras, la gente sí. Recuperado de http://www.fccca.com.ar/noticias. php?idNot $=447$

Hoyt, L. (2006). Importing Ideas: The Transnational Transfer of Urban Revitalization Policy. Intl Journal of Public Administration, 29, 221-243.

Hoyt, L. \& Gopal-Agge, D. (2007). The Business Improvement District Model: A Balanced Review of Contemporary Debates. Geography Compass, I(4), 946-958.

Jacobs, J. (1961). The Death and Life of Great American Cities. New York: Random House.

Ludeña, W. (2002). Lima: poder, centro y centralidad. Del centro nativo al centro neoliberal. EURE, Revista latinoamericana de estudios urbano regionales 28(83), 45-65.

Lorenzen Martiny, M. (2015). ¿La gentrificación rural y urbana como factor de anclaje de la población originaria? Indicios desde Morelos, México. En V. Delgadillo, I. Díaz, \& L. Salinas, Perspectivas del estudio de la gentrificación en México y América Latina (pp. 275-300). México: Geografía para el Siglo XXI.

Mitchell, J. (2001). Business Improvement Districts and the "New" Revitalization of Downtown. Economis Development Quarterly, 15(2), 115-123.

Molinillo Jimenez, S. (2001). Centros comerciales de área urbana. Estudio de las principales experiencias extranjeras. Distribución y Consumo, 57, 27-45.

Muñoz, M. (2014). Las torres en el damero: Transformaciones residenciales en una centralidad de la segunda corona de la RMBA (Tesis de Licenciatura en Urbanismo, Instituto del Conurbano, Universidad Nacional de General Sarmiento, Los Polvorines, Argentina).

Rojas, E. (2004). Volver al Centro. La recuperación de áreas urbanas centrales. Nueva York: Banco Interamericano de Desarrollo.

Vecslir, L. \& Blanco, J. (2014). Movilidad cotidiana y reestructuración de la centralidad en el sur de la Región Metropolitana de Buenos Aires. XIII Seminario Internacional: Red Iberoamericana de Investigadores sobre Globalización y Territorio (RII). Salvador, Brasil: RII-RIER.

Vecslir, L. \& Elimbaum, P. (2016). Centro y centralidades en la Región Metropolitana de Buenos Aires. En C. Jaimes, F. Janches et al. (comps.). Del conocimiento al desarrollo: nuevos desafíos de la universidad en la gestión del desarrollo urbano contemporáneo, 1. ${ }^{a}$ ed. (pp. 420439). Ciudad Autónoma de Buenos Aires: Eudeba. territarios 38 
Vecslir, L., Blanco, J., Nerome, M., Sciutto, F., Maestrojuan, P. y Rodríguez, L. (2017). Reestructuración de la centralidad y movilidad cotidiana en el sur de la Región Metropolitana de Buenos Aires. Revista Transporte y Territorio, (17), 268-289. 